\title{
Motion Control of a Robotic Arm of a Humanoid Robot with Perspective Difference
}

\author{
by
}

Colin Killby

A thesis submitted to the Faculty of Graduate and Postdoctoral Affairs in partial fulfillment of the requirements for the degree of

\author{
Master of Applied Science \\ in \\ Human-Computer Interaction
}

Carleton University

Ottawa, Ontario

(C) 2015

Colin Killby 


\section{Abstract}

This study examines the feasibility of a motion and haptic integrated system for the purpose of controlling a humanoid robotic arm. An Oculus rift head-mounted display was integrated into the system to determine if there was an observable difference between thirdperson and first-person perspective control. We examine different methods of robotic control in humanoid robots and the precedence of head-mounted displays and motion control in current literature, as well as look at vibration as a form of haptic feedback to relay the limitations of the robot. An experiment was completed with the prototype system in which 30 participants were able to complete the given gross and fine motor testing tasks without fail. A learning period was observed when comparing completion times of the first task attempted to subsequent tasks. The majority of participants found the method of control to be intuitive, the inclusion of first-person perspective to be beneficial, and the vibration feedback to be either inconsequential or confusing rather than helpful. 


\section{Acknowledgements}

I would like to thank my research supervisor Anthony Whitehead for providing me this opportunity among many others, as well as for his experienced direction without which this would not have been possible. I would also like to thank Dennis Arsenault for helping to create the framework for this research and for his friendship and guidance. I also thank my family for supporting me through the years. Finally I thank my wife Jennifer Perry for giving me the inspiration and motivation to become the person I want to be. 


\section{Table of Contents}

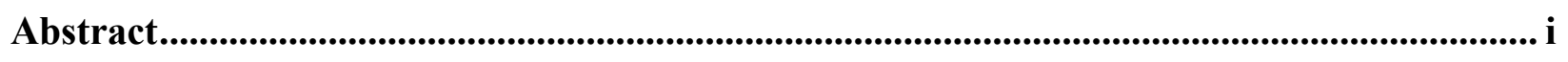

Acknowledgements ................................................................................................................... ii

Table of Contents ..............................................................................................................

List of Figures.................................................................................................................................. vi

List of Tables ................................................................................................................. vii

1 Chapter: Introduction .................................................................................................. 1

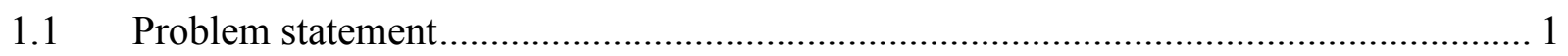

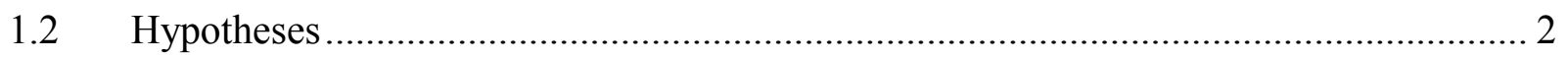

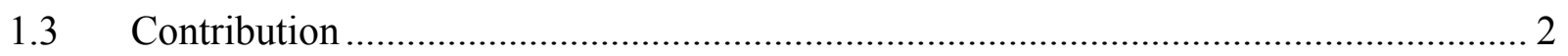

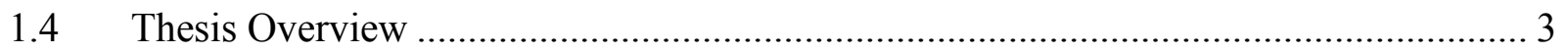

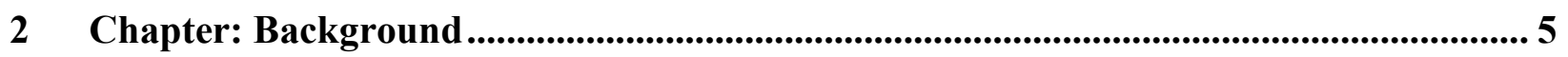

2.1 Marker-Based Motion Capture Systems ………………………………………...... 5

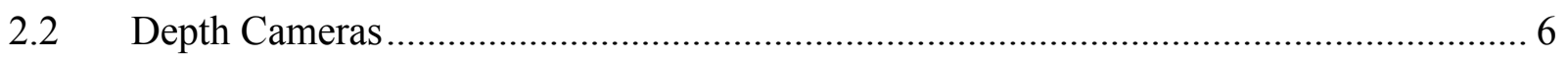

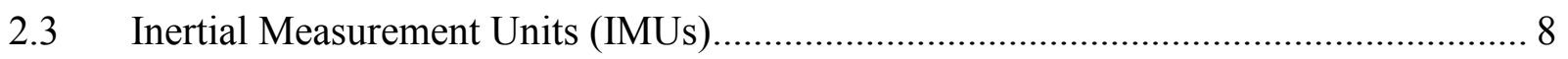

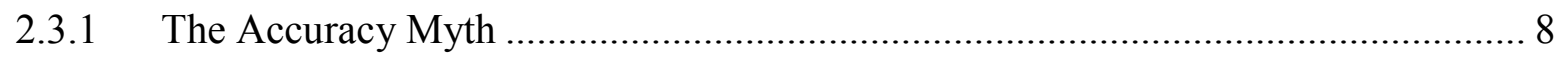

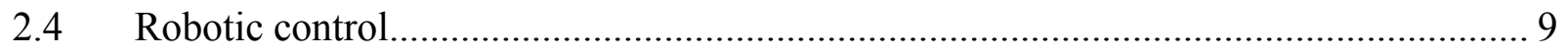

2.4.1 Telepresence Control Using Optical Systems.................................................... 9

2.4.2 Telepresence Control Using IMU systems ......................................................... 10

2.4.3 Haptic Feedback in Robotic Control.................................................................... 11

2.5 Perspective Robotics and Virtual Reality ………................................................... 11

2.5.1 Perspective in Robotic Control ....................................................................... 12

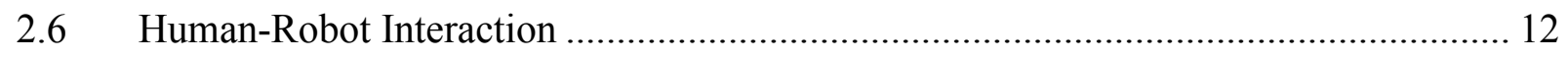

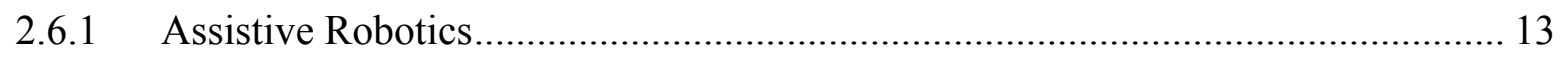

2.7 Wearable Computing and Motion Control ............................................................... 14

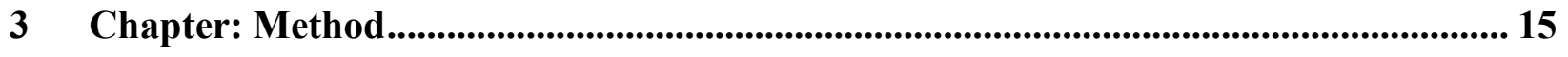

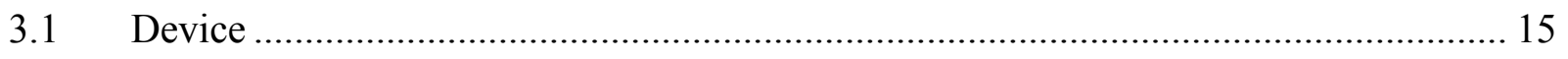

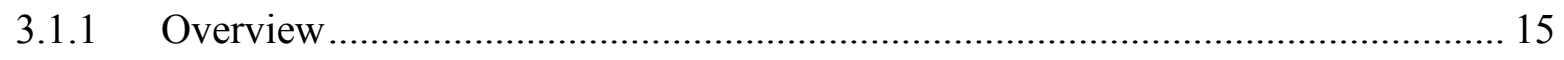

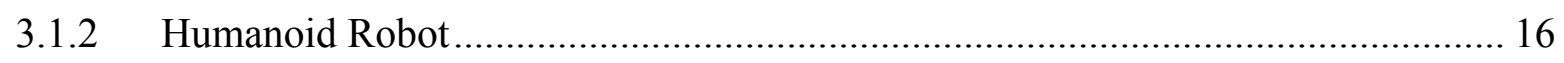

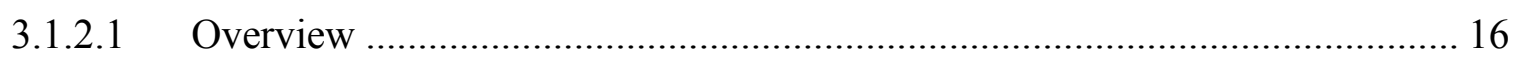

3.1.2.2 Open-Source Framework .......................................................................... 17

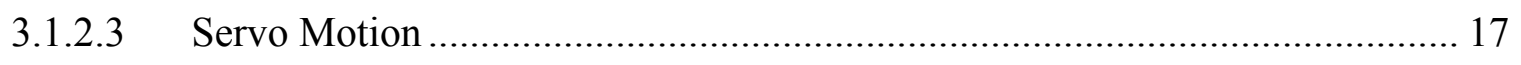

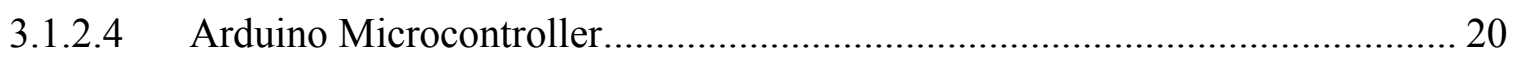




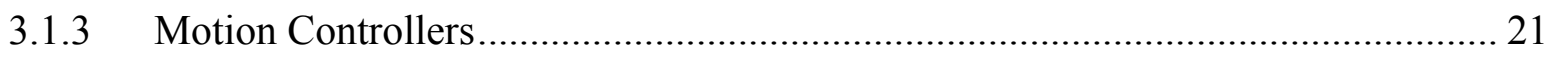

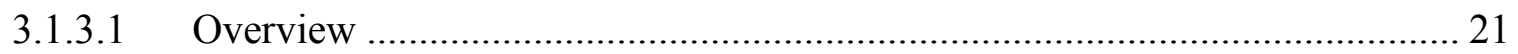

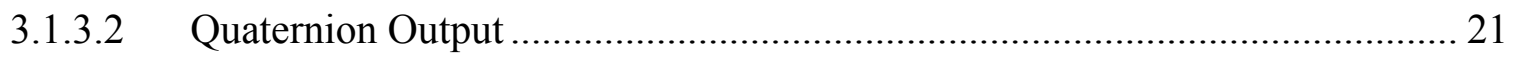

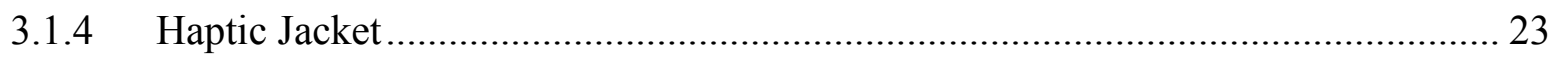

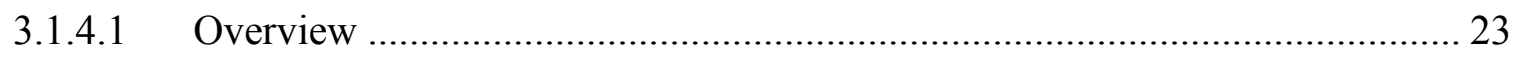

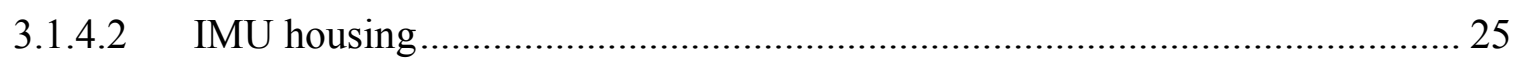

3.1.4.3 Vibration Motors and Pulse Width Modulation ............................................. 26

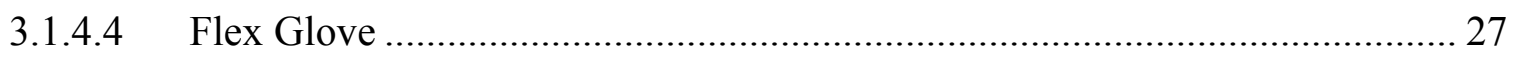

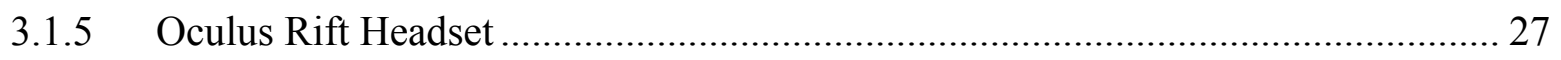

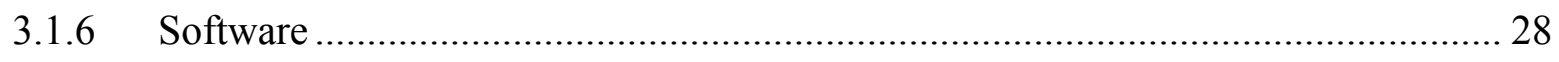

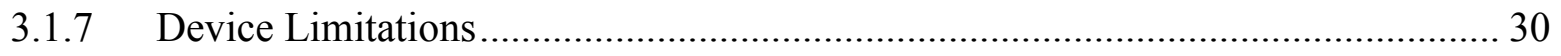

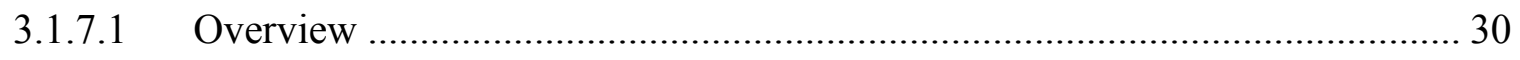

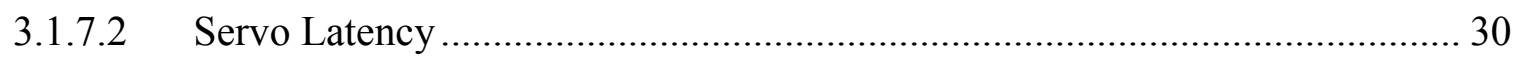

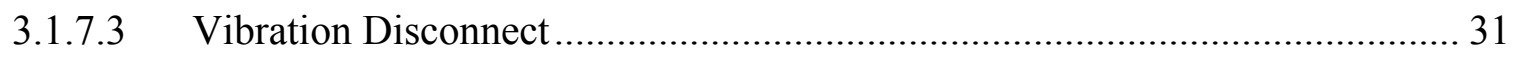

3.1.7.4 Fixed Perspective..................................................................................... 31

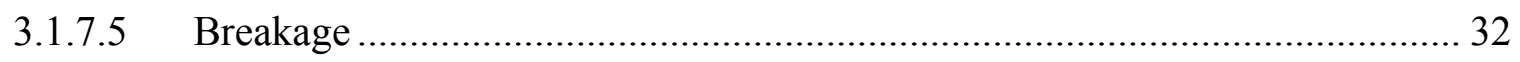

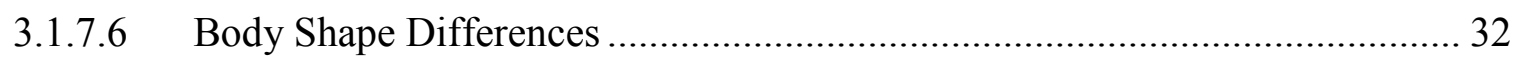

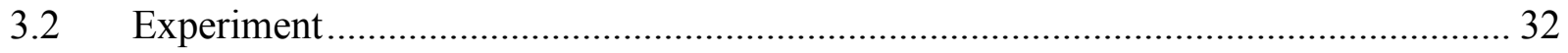

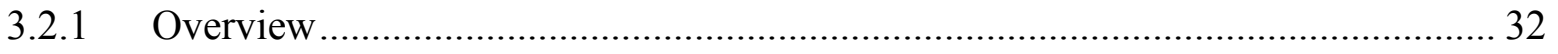

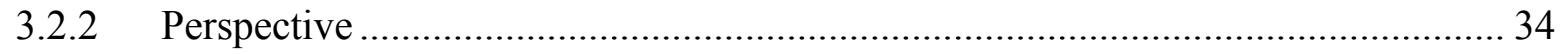

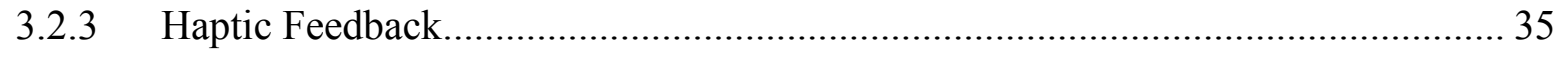

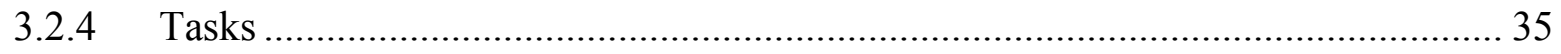

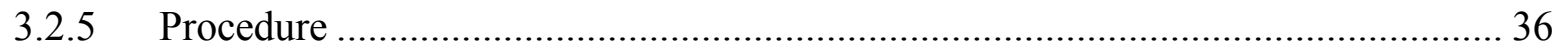

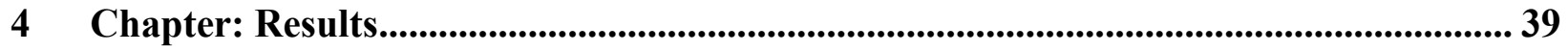

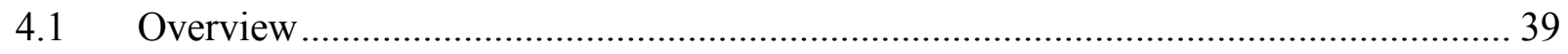

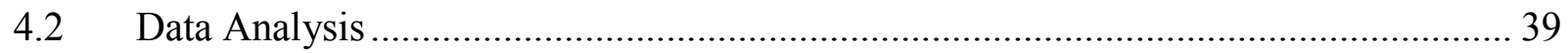

4.2.1 Differences in statistical groups ...................................................................... 39

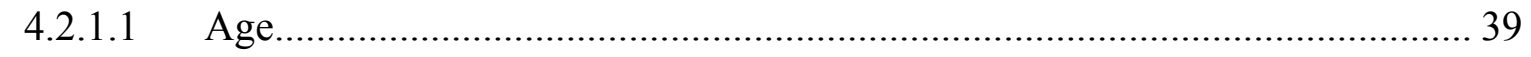

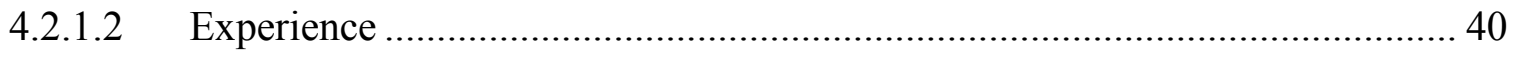

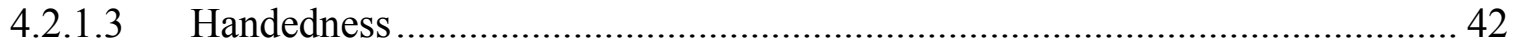

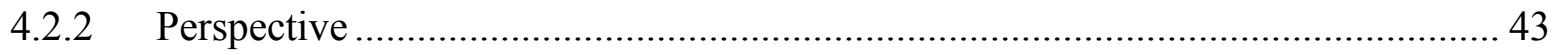

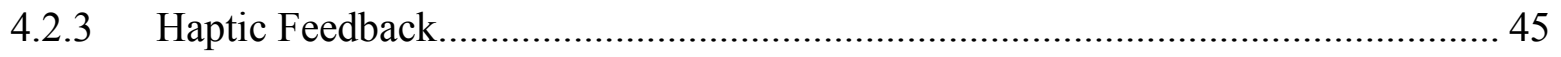

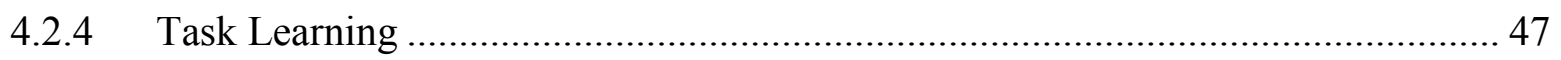

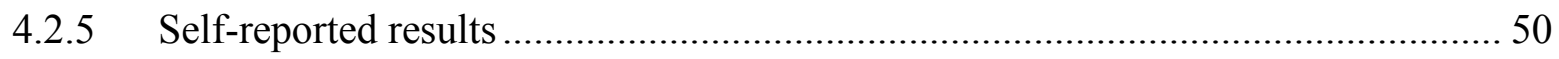




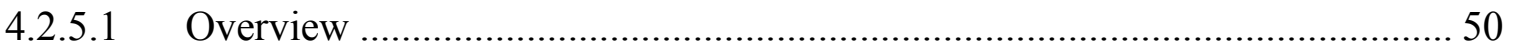

4.2.5.2 Motion Control .................................................................................... 51

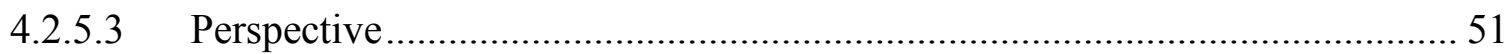

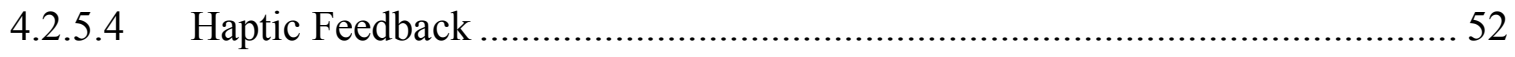

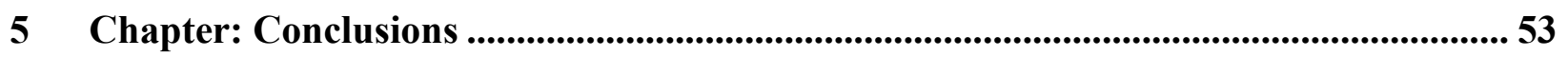

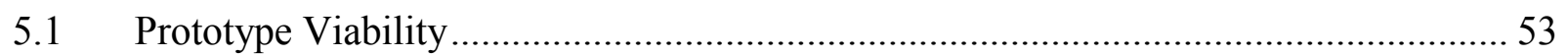

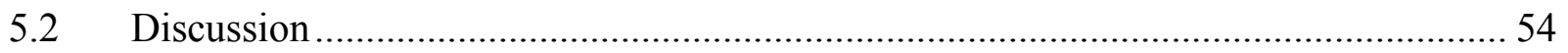

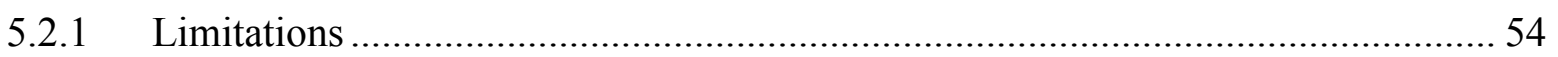

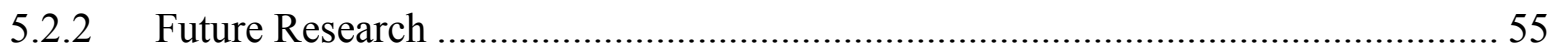

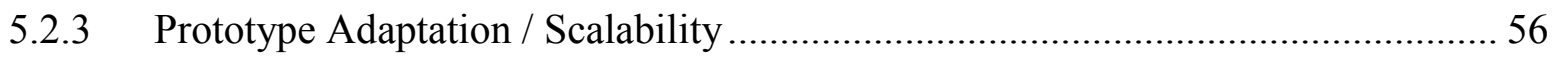

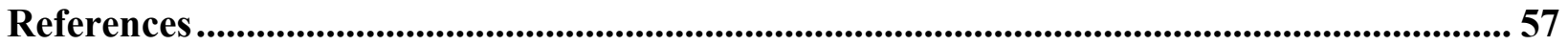

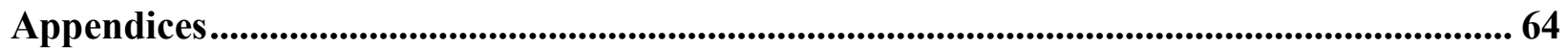

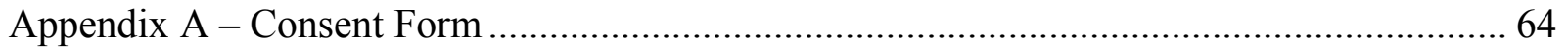

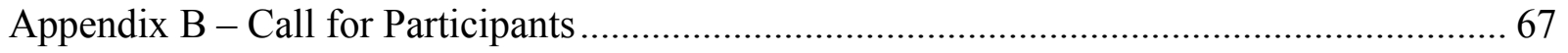

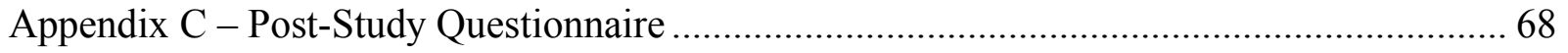

Appendix D - Likert Response Summary .................................................................. 73

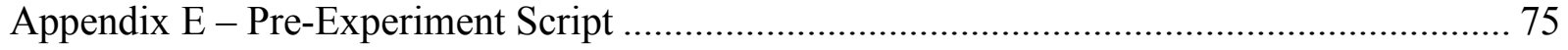




\section{List of Figures}

Figure 1: Camera Motion Capture System Environment …….................................................... 6

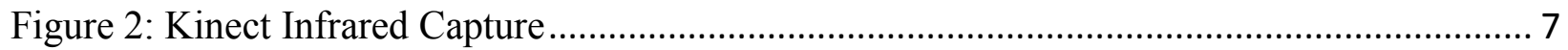

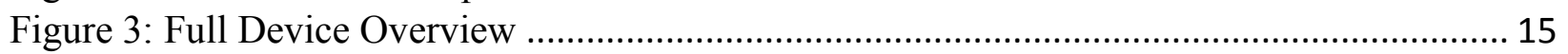

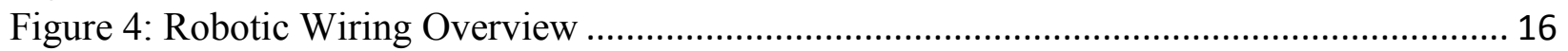

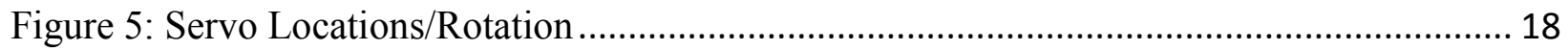

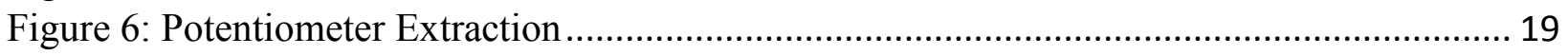

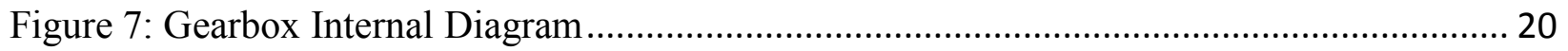

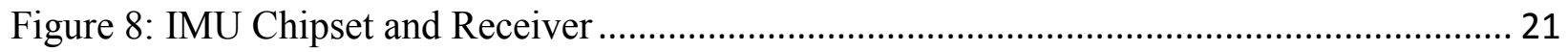

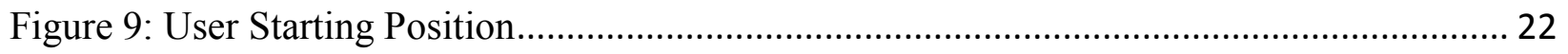

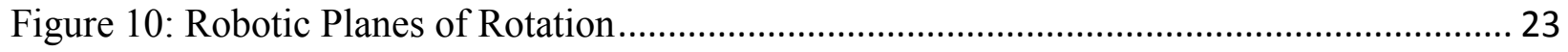

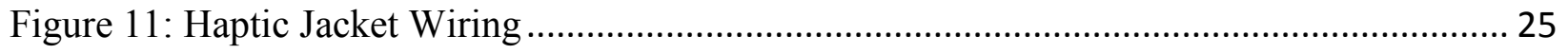

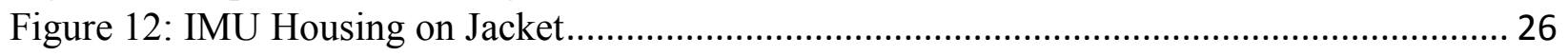

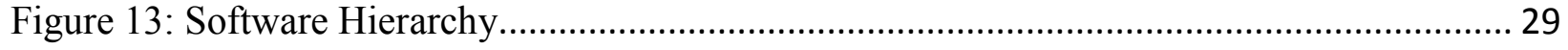

Figure 14: Servo Latency Times for 20 Degrees of Rotation ..................................................... 31

Figure 15: Perspective Difference ...................................................................................... 34

Figure 16: Gross Motor Task .......................................................................................... 35

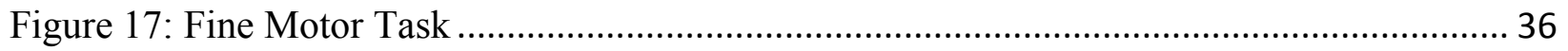

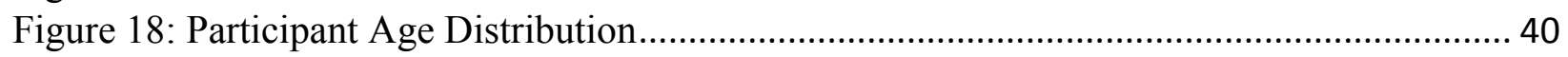

Figure 19: Individual Perspective Differences in Fine Motor Tasks ............................................ 44

Figure 20: First Task vs. Average of Subsequent Tasks............................................................... 47

Figure 21: Average Task Time by Task Completion Order ....................................................... 48 


\section{List of Tables}

Table 1: Task Outline......................................................................................................... 33

Table 2: Mean Task Completion Times Based On User Experience ....................................... 41

Table 3: Individual Variable Comparison between Experienced and Non-Experienced Users ... 41

Table 4: Mean Task Completion Times Based On Dominant Hand .......................................... 42

Table 5: Individual Variable Comparison between Left and Right-handed Users ..................... 43

Table 6: Perspective Comparison of Individual Task Completion Times ................................ 45

Table 7: Vibration Comparison of Individual Task Completion Times ...................................... 46

Table 8: Perspective Comparison without Task Learning ................................................... 49

Table 9: Vibration Comparison without Task Learning ................................................... 50 


\section{Chapter: Introduction}

This dissertation outlines a project that involved building a life-size 3D-printed humanoid robot, through which a user could interact via motion control sensors and virtual reality technology.

\subsection{Problem statement}

Can a device be created for robotic telepresence with current motion capture technology that can be intuitive enough for an untrained person to use it effectively without a learning period?

As communication technologies have become more sophisticated we have begun to see an emergence of telepresence applications that allow for realistic human interaction without physical interaction through programs such as skype, facetime or snapchat. As robotic technologies also become more sophisticated, robotic telepresence has begun to take a more important position, as it bridges the physical gap of telepresence and allows the user to interact with the world instead of being a passive observer.

Intuitive robotic control through telepresence also allows for many new and important applications that may not even be possible through normal human physical interaction. A robot can be used for assistive purposes, allowing a disabled person the ability to perform difficult tasks. Robots also have the potential to be stronger and use sensors not available to humans, providing controllers with superhuman abilities they could not normally possess.

In order to facilitate the ease of use of this emerging technology, it is important to understand the best practices for maximum usability, one of the most important being system intuitiveness. This experiment was created with the intention of adding to the current knowledge base on usability of telepresence robotics. 


\subsection{Hypotheses}

The following hypotheses were used in the design of the experiment:

1. First-person control will be preferred over third-person control when performing tasks that require fine motor control, due to the perspective matching what the participant is familiar with. This preference will be shown by shorter task completion times when participants are using the Oculus Rift headset for the fine motor task versus the same task from a third-person perspective.

2. Haptic feedback in the form of vibration will be more effective at relaying the robotic range-of-motion limits to the user when it is a binary boundary as opposed to a vibration that slowly increases in intensity as it approaches that boundary. This will be empirically shown by shorter task completion times when users are subjected to Vibration $\mathbf{A}$ as opposed to Vibration B.

\subsection{Contribution}

This study offers the following contributions to current literature on motion control of humanoid robotics:

Although there is precedent in the literature for motion-controlled telepresence robots, this study demonstrates a system that is relatively inexpensive for control as well as an equivalent 3D-printed robotic build, suggesting a system for maximal accessibility.

The prototype control system describes an inertial control system that uses natural human motion as intuitive control, as rated by the majority of participants (83\%). No failures were recorded on given tasks and no prior training was given.

By using inertial sensors, we describe a scalable design that could be extended to include other body joints or adapted to include more robotic movements.

We suggest a system that does not adapt recorded human movement to fit robotic restraints but instead influences human movement to constrain itself to the limitations of the robotic avatar. This allows more direct control of robotic parts without diminishing the intuitiveness of human movement while also providing a more instinctive reaction from the 
robot. This is also suggested as a possible solution to the problem of latency in human-robotic movement matching.

Our system also suggests that more research needs to be conducted to determine if a perspective difference has a significant impact on robotic control tasks.

The study describes the importance of usable feedback in relating the robotic limitations to the human controller, furthers the understanding of this feedback, and suggests possible areas for future research into feedback for telepresence robot control.

Finally, the research clearly defines the existence of a learning effect even though natural motion is used as the form of control. This learning effect is analysed in respect to the intuitiveness of the system as well as the effect on the hypotheses and results.

\subsection{Thesis Overview}

The thesis begins with an outline of the contributions of this experiment. We then perform a survey of current motion capture technology and its relevance to robotic telepresence, which helped form the hypotheses of this research, in Chapter 2: Background. A possible gap in the research literature is identified and is also used in the experiment formation. The current literature on telepresence motion control and perspective is used as a basis for this experiment.

The constructed device is then described in detail in the subsequent Section 3.1: Device. This includes the aforementioned humanoid robot, the motion control system, the haptic feedback jacket and the virtual reality headset used for perspective difference control. The possible limitations of the prototype device are also discussed in detail.

Section 3.2: Experiment outlines the experiment that was completed with the prototype device. This experiment involved a sample of 30 participants that used human motion to control the humanoid robot in a series of tasks with two separate degrees of motor control, two separate haptic feedback styles, and two separate perspective views. The participants completed a task for each possible state of these variables. The following Chapter 4: Results describes the results of this experiment, offers a statistical analysis and discusses the self-reported results of participants on the post-study questionnaire. 
Finally, in Chapter 5: Conclusions and following Section 5.2: Discussion we discuss the outcome of the experiment in regards to our originally proposed hypotheses, reconvene on the viability of the prototype post-study, and describe possible future areas of research with respect to the limitations of this study. 


\section{Chapter: Background}

This chapter outlines current methods of motion control for human motion capture, including the advantages and disadvantages of common methods. This will then be given context in current research into motion control of robotics. We will then describe an observed gap in human-robotic interaction research regarding different perspective views for robotic control in the context of telepresence robotics and virtual presence.

Three of the most common types of human motion tracking are optical marker-based systems, optical depth camera systems, and inertial measurement unit (IMU) systems. These are presented and compared in Sections 2.1 to 2.3. Robot control is covered in Section 2.2, where we also discuss telepresence control using these systems. Perspective in robotics is then discussed in Section 2.5, followed by a review of the current state of wearable computing in Section 2.7.

\subsection{Marker-Based Motion Capture Systems}

The traditional form of motion capture involves a sterile room of infrared cameras that surround a capture space (as in the Vicon system)[9]. The subject must wear reflective markers specifically designed for camera capture. The advantage of marker capture systems are in a much greater capture accuracy, generally found to be less than a millimeter [10][52][53]. This is therefore very useful for accurate capture of slight motions.

Capture accuracy, however, can be affected by a number of environmental factors. These include: marker size / distance [11][12], number of cameras / positioning [11][12][13], environmental lighting [12], and occlusion as a result of body positioning or environmental effects [13]. Marker size can affect how easily the camera system can detect the position of the marker, and a system with more cameras can more easily detect markers due to the increased capture area and angles of detection. Occlusion refers to the accidental covering of markers through body positioning, leading the markers to be obscured from the point of view of the capture cameras. 
The relative high cost of these systems make them unreasonable for general use.

Moreover, the space requirements make such capture systems only usable in one preconfigured environment [14] (see Figure 1: Camera Motion Capture System Environment). As a general input device, the calibration requirements and the mere fact that they must be used in very controlled environments makes such systems unsuitable for many applications, especially robot control in unconstrained environments, which this thesis addresses.

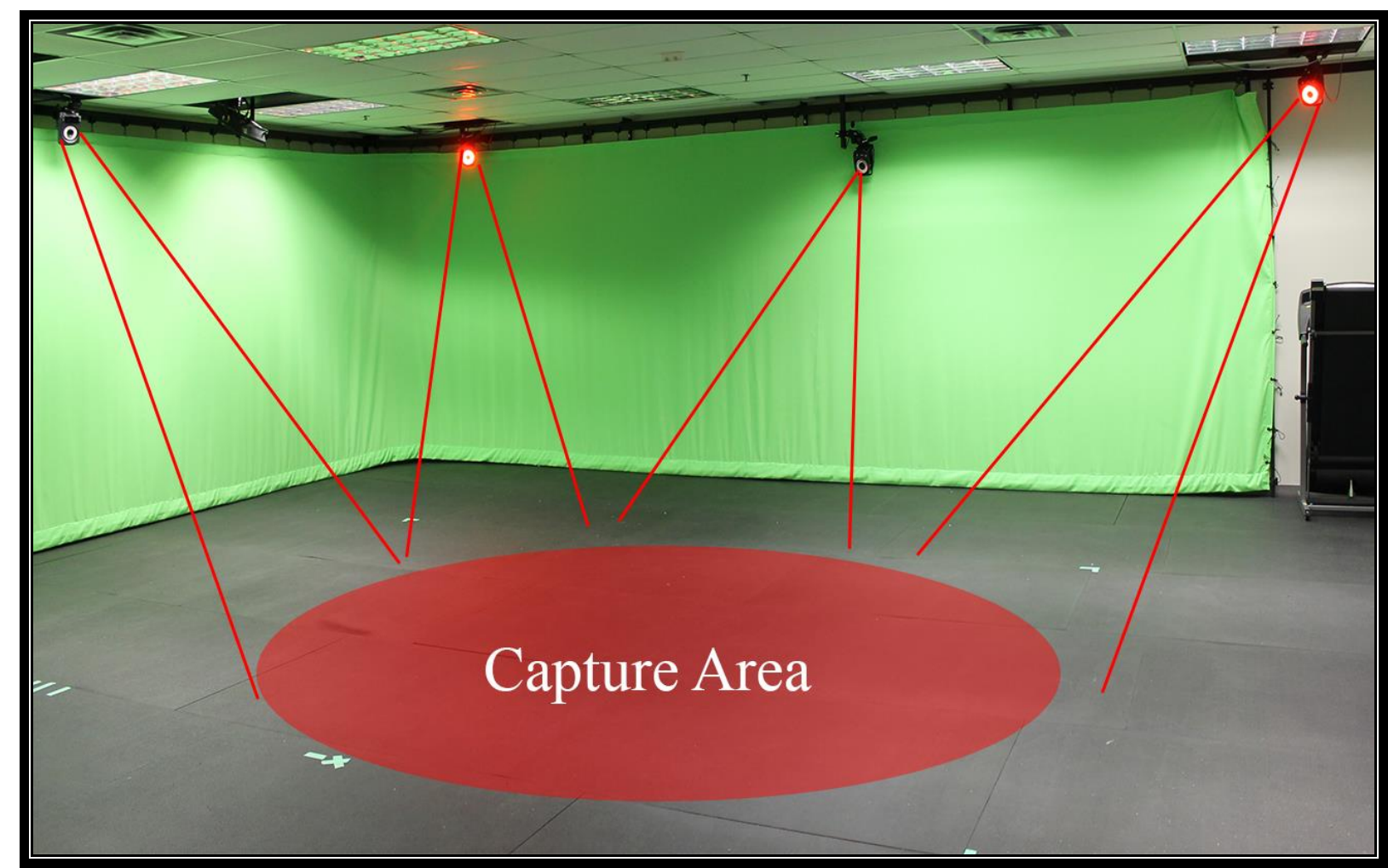

Figure 1: Camera Motion Capture System Environment

\subsection{Depth Cameras}

Depth camera tracking is becoming more popular due to inexpensive entertainment devices such as Microsoft's Kinect [30][54], which is composed of an infrared emitter, depth camera and an RGB camera, as well as a development kit that allows for skeletal joint tracking and facial recognition. The Kinect system senses depth by emitting an infrared light pattern into the environment and creating a depth map of these dots using the infrared camera [31] (see 
Figure 2: Kinect Infrared Capture). For skeletal tracking, the Kinect uses a large library of depth-sensor training data to differentiate separate human body parts, and then estimates the locations of skeletal joints on the current image from the point cloud data that the depth sensor generates. This library is included with the Kinect sensor, making skeletal tracking very accessible.

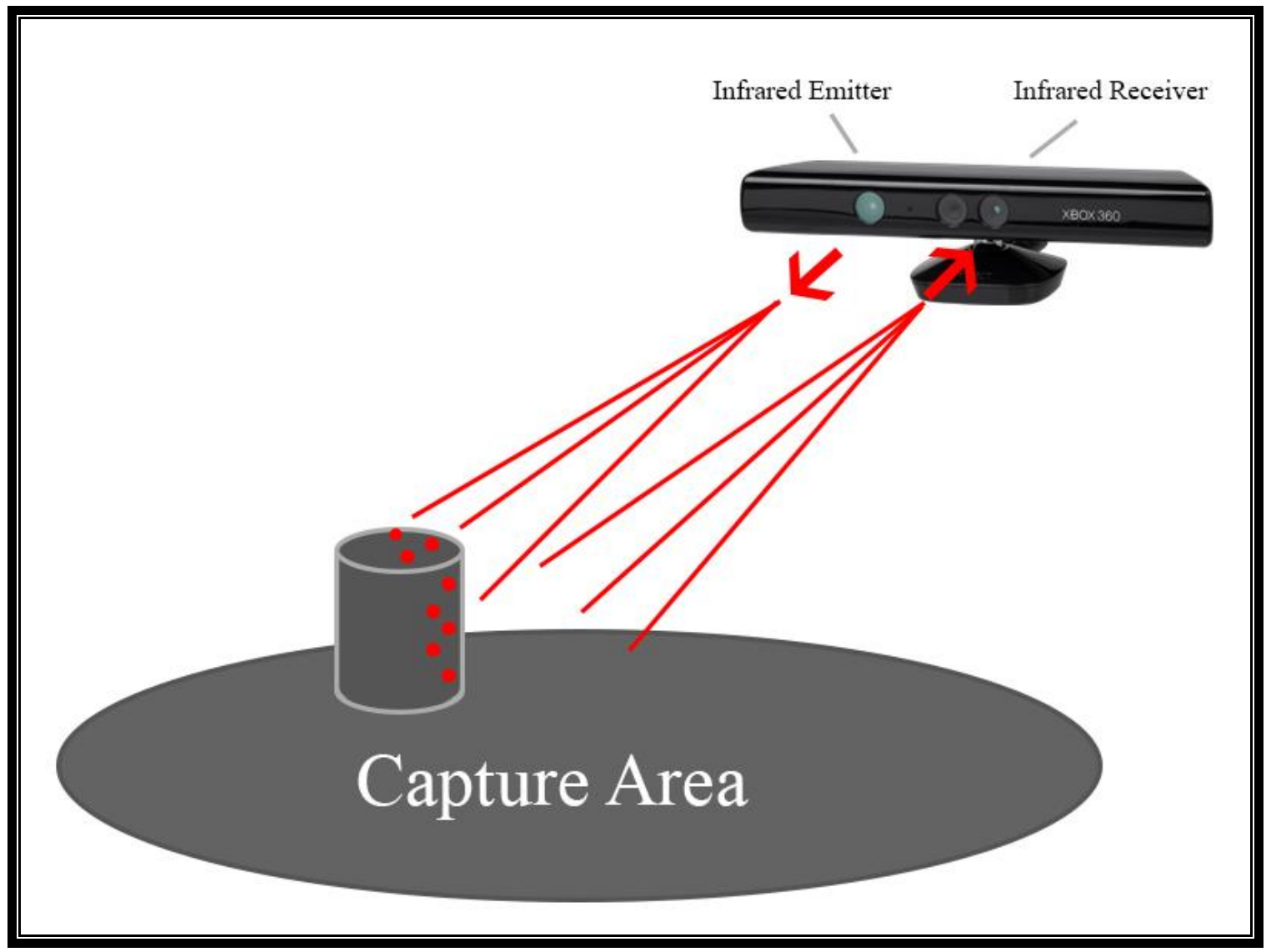

Figure 2: Kinect Infrared Capture

Depth camera tracking like the Kinect also suffers the same occlusion disadvantage as marker capture systems although usually to a much greater degree as a result of a smaller range of capture corresponding to a smaller number of cameras. As well, depth cameras that use an infrared pattern projection system are only useful in an indoor environment. 


\subsection{Inertial Measurement Units (IMUs)}

Inertial measurement sensor motion capture requires the direct application of a series of fused sensors (including accelerometers, gyroscopes and magnetometers) to the body. This type of sensor network has been shown to be useful in entertainment and exercise motion-capture applications, both for its relative low-cost and encouragement of active play [17][18][19].

The main advantage of wearable IMU sensors is the ability to track motion in any environment thus increasing the number of useful applications [14] as well as avoiding the issues of occlusion that are common in optical systems. A wireless IMU system allows for captures in a natural setting for situations that would be difficult to capture traditionally (such as skiing [14] or skydiving), as well as the convenience of motion capture not being tethered to a single location.

\subsubsection{The Accuracy Myth}

There is a perceived inaccuracy of IMU systems when compared to traditional optical motion capture systems due to the suggested high rate of sensor rotation error during dynamic movement [4][5]. This is especially amplified when compared to optical tracking systems, like the Vicon camera system, which boasts sub-millimeter accuracy [2] in their marketing efforts. However, a recent study by Godwin et al. [2] observed modern IMU error rates and found a rotational error of less than a degree when the sensor is motionless, and less than four degrees during constant motion, and found similar error rates when compared to the optical Vicon system in an ideal environment. Studies have also determined that calibration routines can be used with IMU sensors to further reduce tracking error by matching sensor coordinate systems to an external system [2][3]. One such study that provides the sensor framework for this experiment observed a significant reduction in sensor drift errors when calibration was applied [1] without the use of magnetometer anchoring. Magnetometer anchoring would further improve the accuracy of such a system. This suggests that modern IMU sensors are suitable for most applications that traditional optical motion tracking is currently used for when employing custom fusion algorithms [4]. Moreover, the broader range of use in different situations (i.e. outdoors) makes them particularly attractive for motion capture applications in unconstrained environments. 


\subsection{Robotic control}

A noted problem in robotic control using natural human movement is the ability of the robot to effectively mimic swift and complex human motion. A study by Pollard et al. [6] suggested an algorithmic solution in which motion data including joint velocity and angles could be scaled to constrain the human motion to a humanoid robot's range of motion. This technique has its drawbacks, as subtle human movements are lost. This technique is also only effective with pre-recorded motion because of the previously mentioned difficulty of matching robot speed and precision to human motions as well as the time complexity needed to scale the movements.

A possible direction of research could come from studies applying real-time human motion to animated characters. Shin et al. [7] suggested an importance-based real-time kinematic interpretation algorithm that would decide the importance of joint angles and end effector locations based on situation. Instead of just using the desired end position of limbs like hand position for a grasping task, this approach takes into account joint angles and gives them an importance level to preserve using a series of algorithms. This approach still retains the problem of discrete aspects of the human motion not being retained on a 1-to-1 scale.

Another possible direction is gesture recognition [24], which has the advantage of being able to detect specific motions in real-time, and map them to repeatable and predictable robot movement. This, however, is not useful for tasks that require unique motions not found in the gesture library, or for tasks that require fine motor control precision as critical for success.

We next examine research in robotic telepresence control for both optical and IMU based systems.

\subsubsection{Telepresence Control Using Optical Systems}

Due to the relatively low barrier-of-entry, the majority of studies using optical-based realtime motion capture for robotic control have used depth cameras similar to Microsoft's Kinect sensor, whose development kit provides skeletal tracking algorithms with the camera at a low cost. A multitude of studies have provided different proof-of-concept control schemes using the Kinect as the main control input [48][49][50][51]. 
Many studies have used the Kinect's built-in tracking system as the basis of gesture recognition for robotic teleoperation with some degree of success [35][36], allowing the user to relate natural motions to robotic actions, although not on a 1-to-1 scale.

The Kinect sensor is also capable of using its skeletal tracking software to transmit joint angles to a robotic counterpart in real-time [33][34][37]. However, given the small capture space and single-camera fidelity of the capture, the accuracy is limited, as are the practical applications.

\subsubsection{Telepresence Control Using IMU systems}

There is some precedence of using IMU sensor systems for robotic motion control. One such study by Miller et. al. [15] developed an IMU system for controlling NASA's Robonaut [20], a humanoid telepresence robot designed for use on the international space station. They concluded that such a system could reliably control the Robonaut through telepresence movement while retaining the advantages of IMU systems. The problem of human-robot motion matching was again indicated, wherein the human either moves too fast for the robot servos to match or tries motion to compensate for the latency of the robot, suggesting that haptic feedback could alleviate the issue.

Another similar robotic build is the Telebot prototype [16], which includes IMU motion control and a head-mounted display, although no publications have been released aside from the initial design of the prototype.

IMU systems can also be useful in assistive robotics, tracking user movement and providing situational support [27].

As modern IMU sensors become more accurate, it seems like an obvious choice for realtime telepresence avatar applications due to the low cost of the sensors, the ease-of-setup, the avoidance of environmental problems like occlusion, and the option for use in unconstrained environments. 


\subsubsection{Haptic Feedback in Robotic Control}

There is some precedence of using haptic feedback in robotic control. This is usually used as a form of sensory feedback to give the user a sense of presence by virtually simulating touching an object, as well as to allow for more accurate control by providing more information about the robot's environment, as used in [70][71]. This is especially useful in robotic-assisted surgery systems, in operations that normally are more accurate with a sense of touch (like being able to feel the flesh when suturing) [69].

In this study, we do not use haptic feedback in the traditional form of creating a virtual object, but instead use it to create a tangible virtual boundary to allow the user to "feel" the limits of the robot.

\subsection{Perspective Robotics and Virtual Reality}

The release of the Oculus Rift [8] in 2012 provided the first easily-attainable head tracking and virtual reality head-mounted display (HMD). This also allowed for more feasible research into the domain of virtual reality, the implications of which in turn have driven more research into motion control to allow for a more immersive virtual experience in terms of presence.

With the onset of this increased availability of these virtual reality systems, many telepresence robotics systems have integrated some form HMD to provide the perspective of the robot to the user, as in [15][16]. However, a possible limitation of HMD technology is the onset of "cybersickness" that has been reported when using virtual reality and includes symptoms of nausea, discomfort and disorientation [40][46]. It is possible that individual differences may leave some users more susceptible to cybersickness than others [41]. The underlying cause of this sickness is not yet completely known and is still a prominent topic in research as virtual reality headsets become more mainstream since this side effect may slow adoption of the technology. 


\subsubsection{Perspective in Robotic Control}

A discernable gap in the research literature is evident when it comes to the most efficient perspective for telepresence or avatar robotic control, with the majority of studies not addressing the possibility of perspective differences at all. We have seen from virtual reality studies that there is some debate on the use of different perspective modes. The majority of studies done with motion control of a robotic avatar either utilize a third person perspective in the same room as the controller (as in [24][33][34][37]), or a first person perspective for use with telepresence robotics without questioning the effect different perspectives could have on the operation (as in [15],[16],[32]). Some studies provide the assumption that a first-person perspective will provide a feeling of virtual presence to the user due to an egocentric perspective or a more natural control [32], but this assumption has not been adequately explored or compared. Formal comparisons of perspective differences do not exist in these studies.

An experiment on robotic teleoperation by Jun [38] suggested that more research into perspective differences is required, when it was found that a group with a first-person perspective performed with $25 \%$ more elapsed time than a group that was allowed both third and first person perspectives. A study by Okura et al. [39] also confirmed that the addition of another viewpoint allowed for more accurate teleoperation.

The question of presence correlation to viewpoint has been studied in the field of virtual reality by Rybarczyk et al. [42], which found that a third person view allowed for more precise learned control of the avatar's limbs, although the self-reported feeling of presence was higher in a first-person perspective. The question of whether a perspective difference is beneficial in controlling telepresence robotic avatars becomes the basis of our first hypothesis.

\subsection{Human-Robot Interaction}

Human-Robot Interaction (HRI) has many interesting aspects that could lead to important research questions, however for the purposes of this study we focus mainly on control interactions as opposed to autonomous robotic interactions with humans. Although this study focuses on robot telepresence control, it is still important to also take into consideration the perceived interaction with the avatar. 
Tsui et al. [25] performed a survey of minimal non-manipulative telepresence robots and found that human poses lead to more perceived positive interactions with coworkers (i.e. eye contact, facing coworkers, and adaptive vocalization). It was also found that a control scheme that can reduce the cognitive load of the user would lead to more positive interactions, so an intuitive system is ideal.

Kristofferson et al. [28] found a correlation between robot formation (i.e. spatial position and rotation) with the human subject and perceived quality of interaction as well as feeling of presence for the controller. It was hypothesized that if the telepresence avatar moved into a similar formation as a human would when interacting (such as following, face-to-face or side-byside) there would be a much higher perception of co-presence.

It was also found that unconscious behaviours such as breathing or blinking help to improve the quality of interaction by Sakamoto et al. [29], who built a realistic android for robotic telepresence. With this addition the human participants felt more of a presence interacting with the android than with the same controller through a video monitor.

If the consensus is supported that robotic interactions are more pleasant for the human when having human-like interactions, then it stands to reason that human-like motion would also be a preferred method of interaction, as well as being an intuitive method of control.

\subsubsection{Assistive Robotics}

In recent years, robots have been emerging as assistive devices for certain at-risk populations such as seniors or the disabled. Some of these devices are designed with physical disability in mind, such as addressing mobility [73] or physical rehabilitation [74]. Some have also been designed as companion robots, and have been shown to be just as effective with seniors as real pets in reducing stress, like Paro the robotic seal [75].

Robots have also begun to be used to assist those with social disabilities [76], such as the Keepon robot [72], which was designed to help children on the autism spectrum interact and understand non-verbal expression and emotion. 
Usually, these studies focus on only one side, being either physically assistive or socially assistive, with few studies examining a system that provides both.

\subsection{Wearable Computing and Motion Control}

Optical motion tracking requires a lab environment, which increases costs and limits the situational context of capture, and depth cameras like the Kinect have a very limited frame of capture. In recent years, wearable computers have seen a successful emergence in the commercial market. Devices range from simple Bluetooth and cell-phone sensors to the recent augmented reality devices, such as the Google Glass [23] head-mounted display which uses a sensor similar to the inertial sensors used in this study. The Fitbit [21] pedometer is another example of a commercially successful wearable that utilizes an accelerometer for relatively basic motion tracking. The Fitbit reported a \$745 million dollar net revenue in 2014 up from \$271 million in 2013 [22], clearly demonstrating a public demand for new and useful wearable devices.

As the demand for wearable computing increases, it stands to reason that the population of users will be more accepting of wearable sensors as a method of control for many applications. Many sensors used in motion capture, such as accelerometers and gyroscopes, already exist in modern user's smartphone devices. Studies have been completed to examine the viability of using just the sensors in these devices for motion capture and human motion recognition [58][59], such as examining algorithms for accurate capture from a loosely attached device [56], or using the smartphone data to determine if a user has fallen and in peril [57][60][61]. This type of motion monitoring may become preferred by the general user, as it does not require the application of additional sensors or markers, and only requires a device which is already being carried on his or her person. However, due to the complexity of motion that is needed, this type of motion capture is not advanced enough to be used for our robotic teleoperation purposes. 


\section{Chapter: Method}

\subsection{Device}

\subsubsection{Overview}

The prototype device consists of four main parts: the humanoid robot, the motion control sensors, the haptic jacket and the Oculus Rift head-mounted display, as shown in Figure 3: Full Device Overview. The user wears the haptic jacket to which the motion sensors as well as the vibration motors are attached in order to control the humanoid robot using normal body motion. All four are connected to the main experiment terminal, which is responsible for control of all of the components.

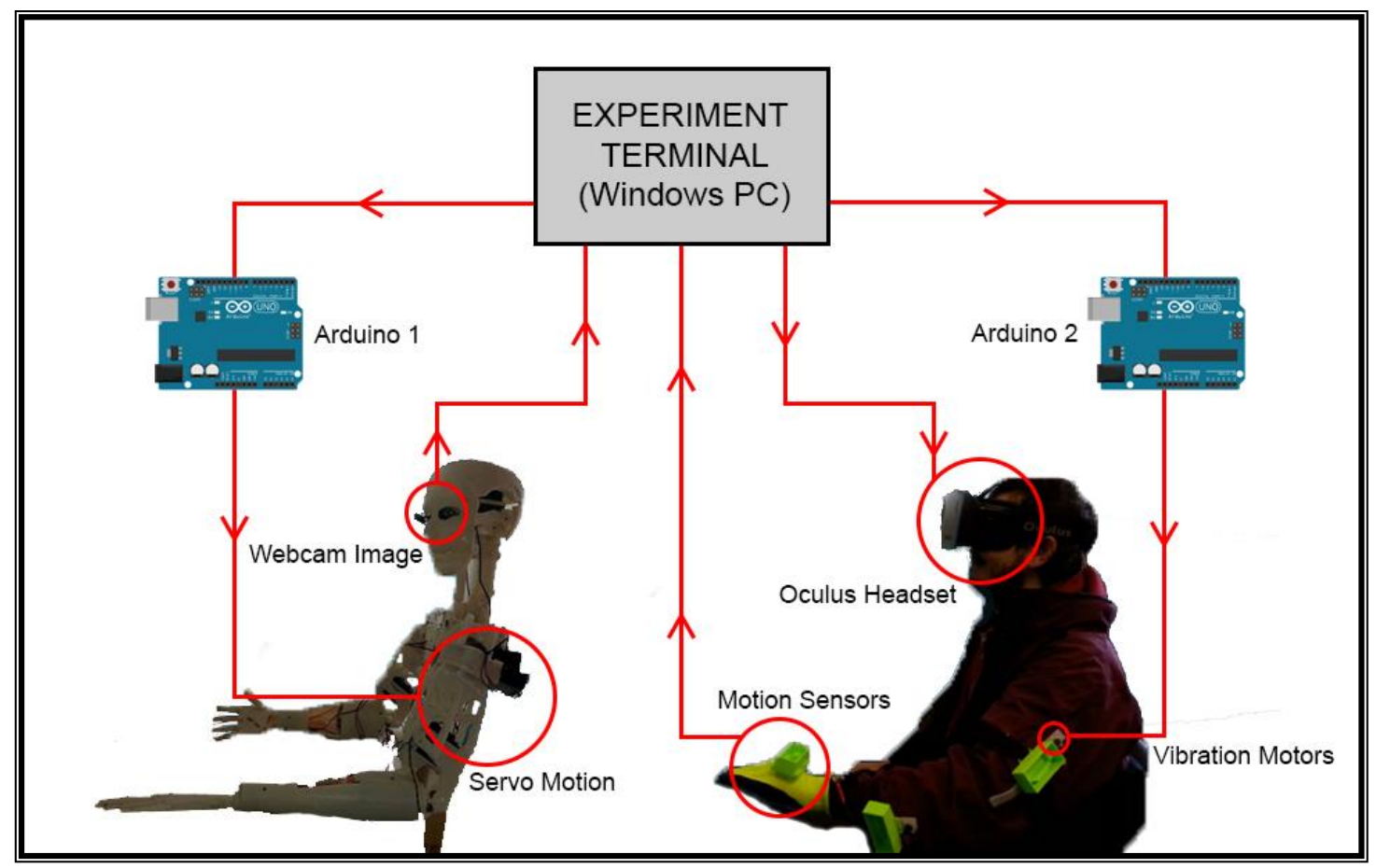

Figure 3: Full Device Overview 


\subsubsection{Humanoid Robot}

\subsubsection{Overview}

An entire human-sized upper torso was 3D-printed and is functional including arm, hand, head and jaw motion. However, for the purposes of this experiment only the left arm was utilized with three points of rotation. Servo motors control the motion of the 3D-printed parts, which are in turn controlled by an Arduino microcontroller directly connected to the experiment terminal (see Figure 4: Robotic Wiring Overview).

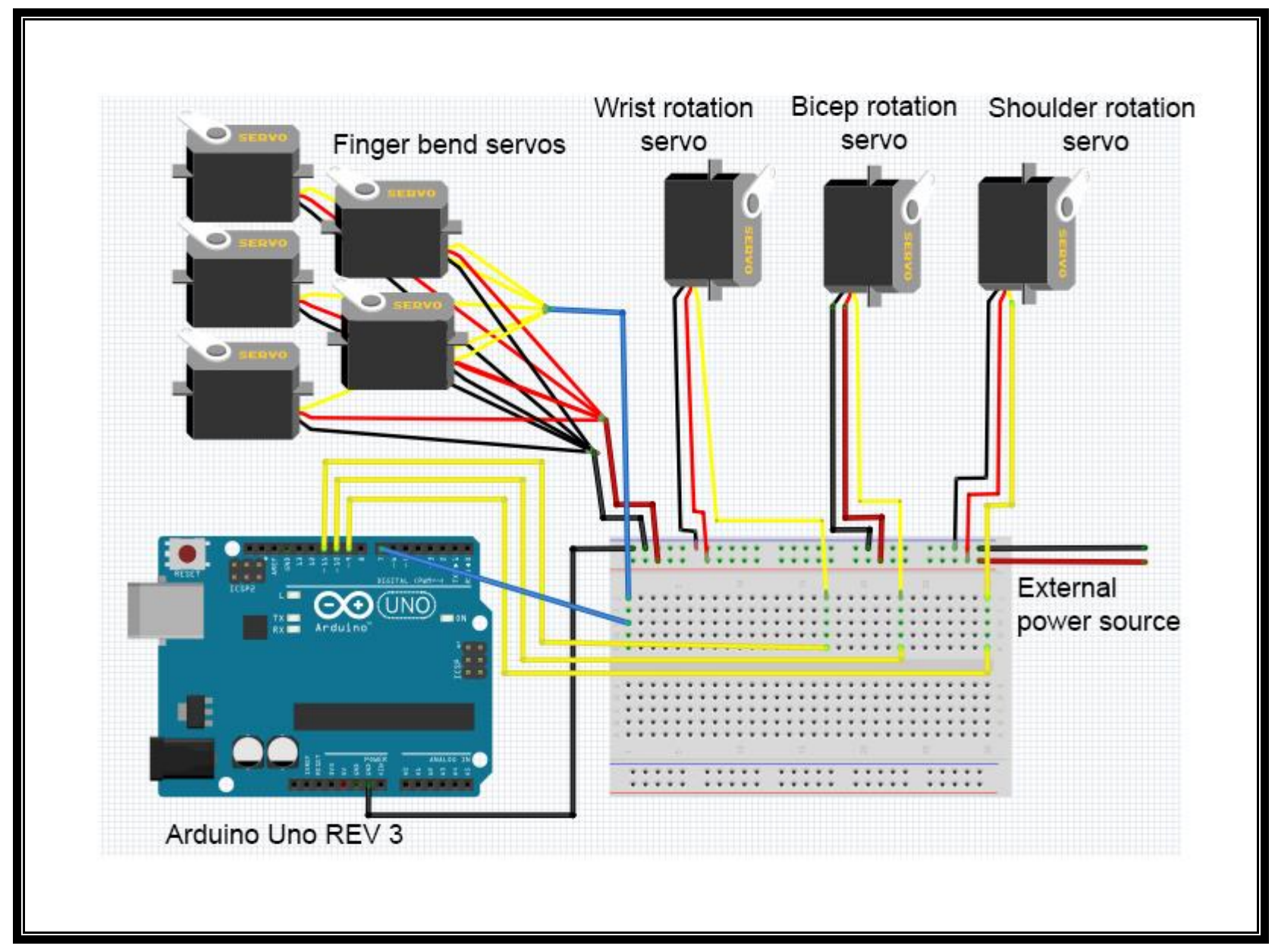

Figure 4: Robotic Wiring Overview 


\subsubsection{Open-Source Framework}

The 3D-printed shell of the robot is based upon a series of open-source 3D model blueprints which the creators have dubbed InMoov [43]. The project's creators set out to construct a repository of files that could be readily available for anyone to use to build their own humanoid robot at a reduced cost when compared to traditional research robotics of similar design, due to the relative lower cost of 3D-printing custom prototypes as well as the benefit of easy CAD software integration [65]. These designs were used in the prototype to reduce costs as well as examine the viability of a personal 3D-printed robot, which led to some limitations of the prototype as well.

The robot parts were printed in ABS plastic using a print bed with a maximum part size of $12^{3}$ centimeters.

\subsubsection{Servo Motion}

Two types of servo motors were used to allow locomotion: the Hitec 645MG servo and the Hitec 805BB servo, the latter being a larger servo capable of more torque [66][67]. The larger servos were used in places of the arm design that required higher torque for operation, namely the shoulder and bicep rotation. Gearboxes were also put in place at these locations to maximize operation power. The smaller servos were used to rotate the wrist and to pull the ligaments connected to the finger joints. The placement is outlined in Figure 5: Servo

\section{Locations/Rotation.}




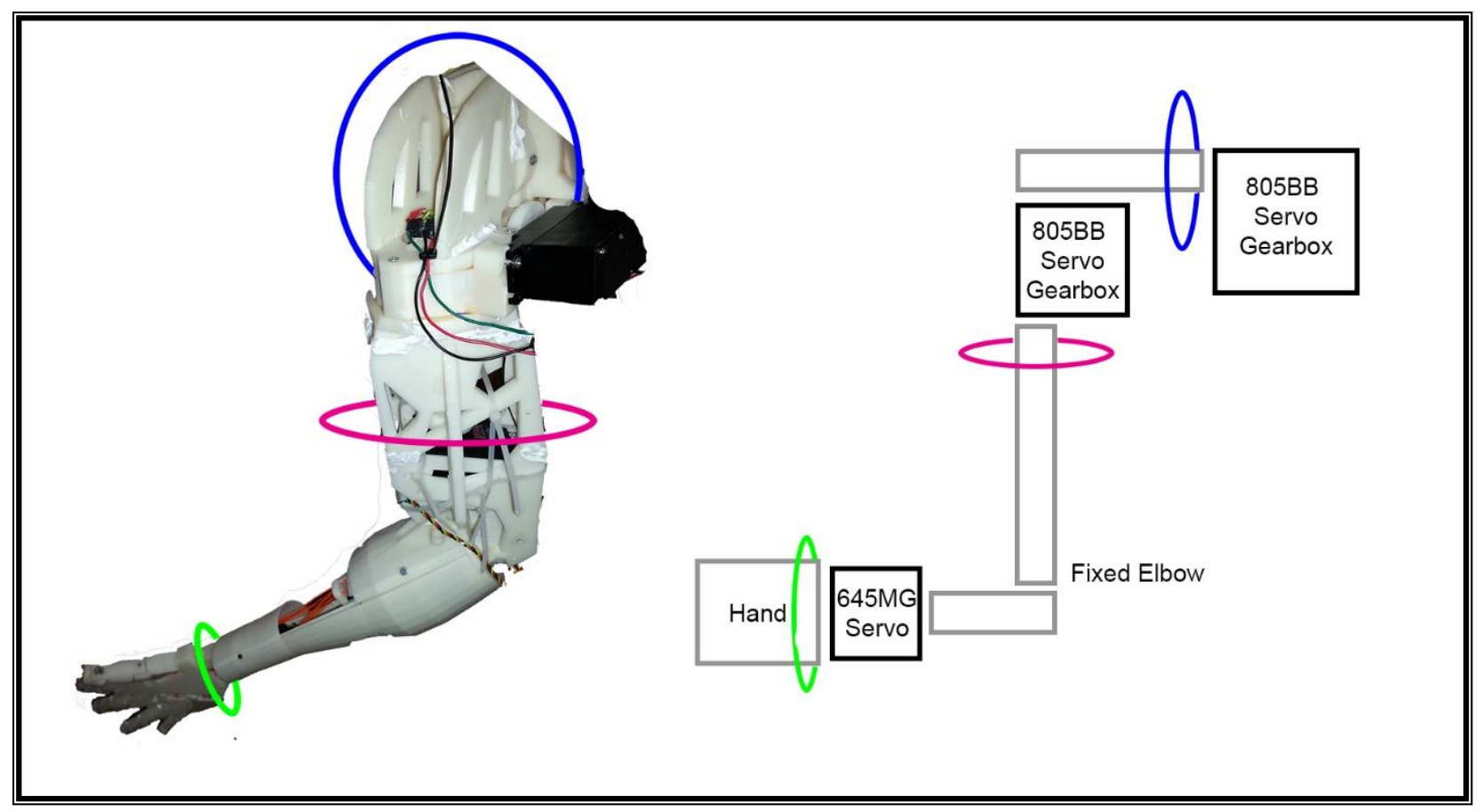

Figure 5: Servo Locations/Rotation

The servo motors used in this prototype rotate around one plane with a maximum rotation angle of 180 degrees. To allow for greater rotation of the servos so that the gearboxes themselves could rotate the robotic parts 180 degrees, the servos were modified by extracting the servo potentiometer and removing the rotation lock (see Figure 6: Potentiometer Extraction). The potentiometer is the component of the servo that keeps track of the servo angle. The potentiometer of the servo was then installed directly onto the point of rotation that it controlled so that the software could directly regulate the angle of the arm joints as opposed to the servo angle. 


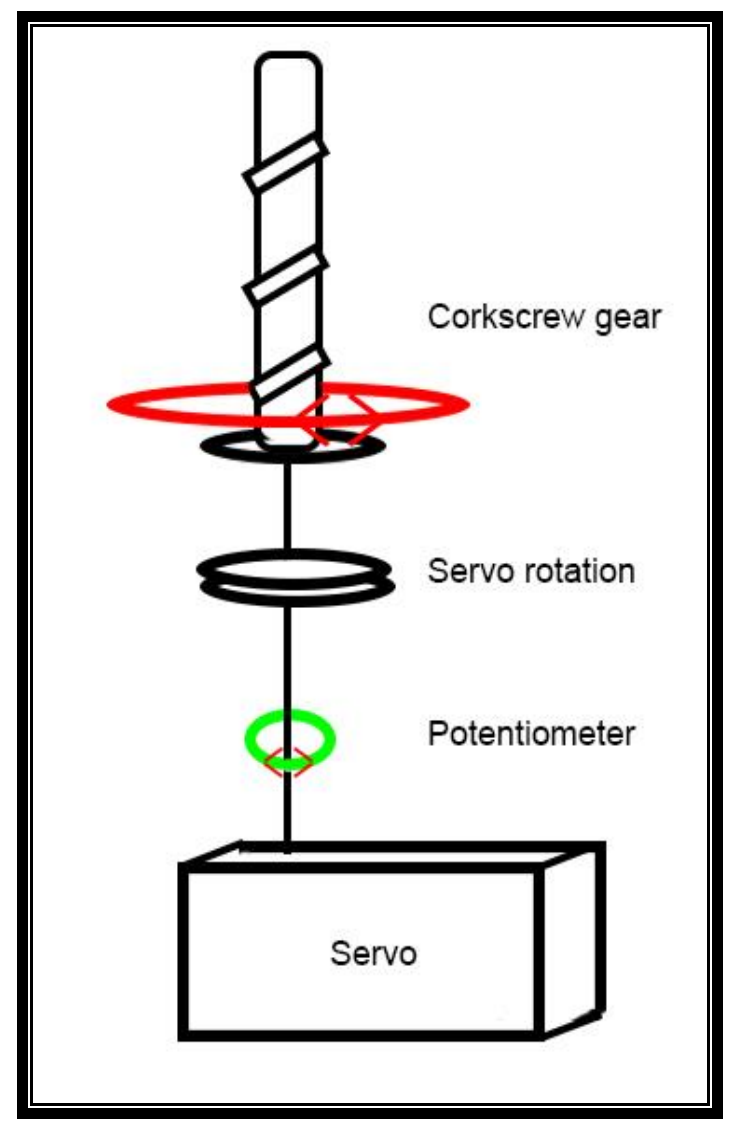

Figure 6: Potentiometer Extraction

The benefit of this technique can most easily be seen when observing the gearbox used for shoulder and bicep rotation, as displayed in Figure 7: Gearbox Internal Diagram. The gearbox is necessary on the planes of rotation with more weight to create a usable amount of torque, and thus to enable a full 180 degree rotation the extraction and reapplication of the servo potentiometer was also necessary. 


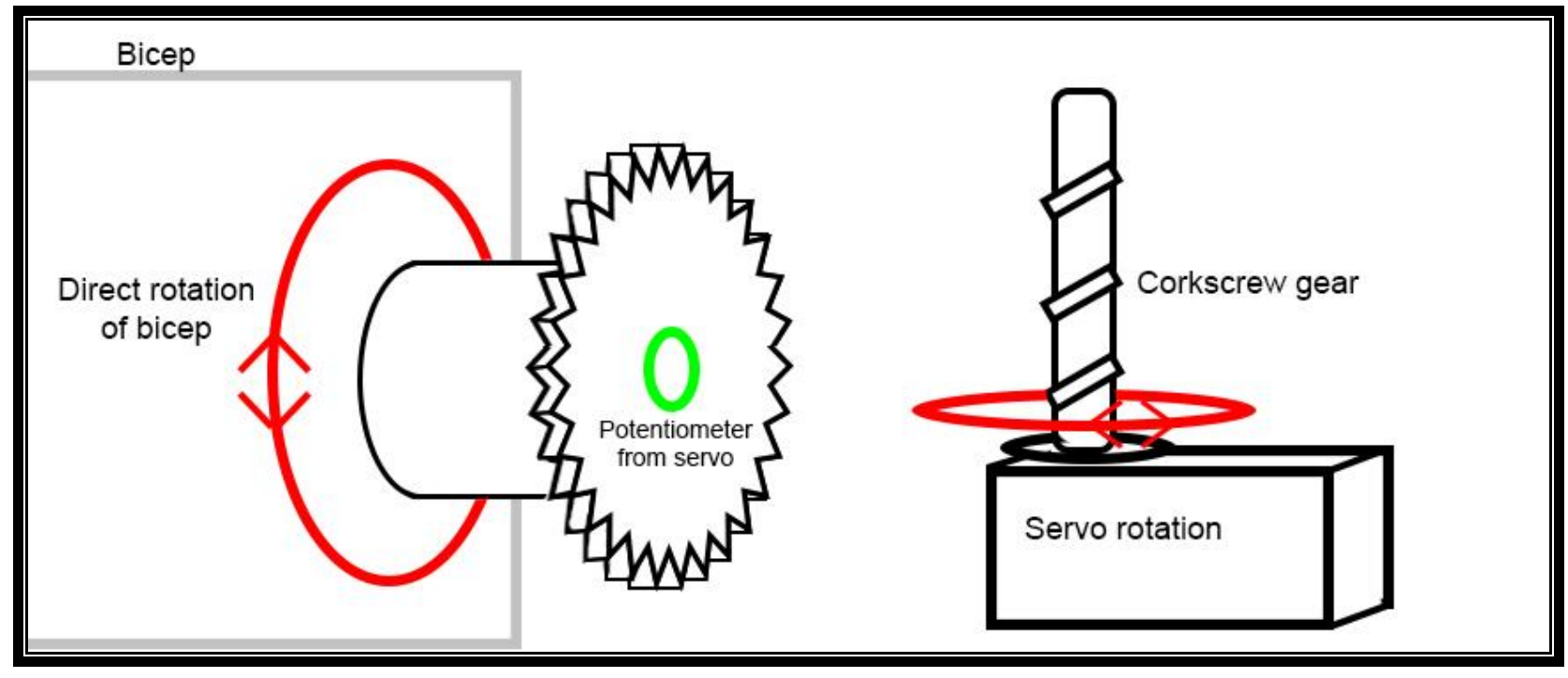

Figure 7: Gearbox Internal Diagram

\subsubsection{Arduino Microcontroller}

Arduino is an open-source hardware microcontroller and software IDE combination [46] that allowed the robot servos to be easily controlled by the main program through a serial connection. The Arduino board is especially useful for prototyping as its functions can quickly be changed by uploading new code to the flash memory. The Arduino IDE also contains built in $\mathrm{C}++$ libraries for servo functions, flex sensor functions and analog sensor functions used in this prototype.

The digital servos are controlled through the Arduino pins, and are kept in constant power to avoid vibrations and inaccuracies. The Arduino is sent updated servo positions every program cycle from the main program, and constantly updates the servo position. The servo position will only be updated should a difference of more than half a degree of rotation be detected from the IMU sensors. 


\subsubsection{Motion Controllers}

\subsubsection{Overview}

This study utilized inertial measurement units (IMUs) to track the motion of the participant at three locations on their left arm. The IMU sensor used was Microchip's nowunsupported Motion Sensing Demo Board, which is composed of an accelerometer and a gyroscope chipset [68]. The device also required a wireless radio receiver connected via USB to the main experiment terminal to receive data from the IMU sensor (as seen in Figure 8: IMU Chipset and Receiver). These specific sensors were used because the framework of this experiment builds upon a previous experiment from the same lab by Dennis Arsenault [1].
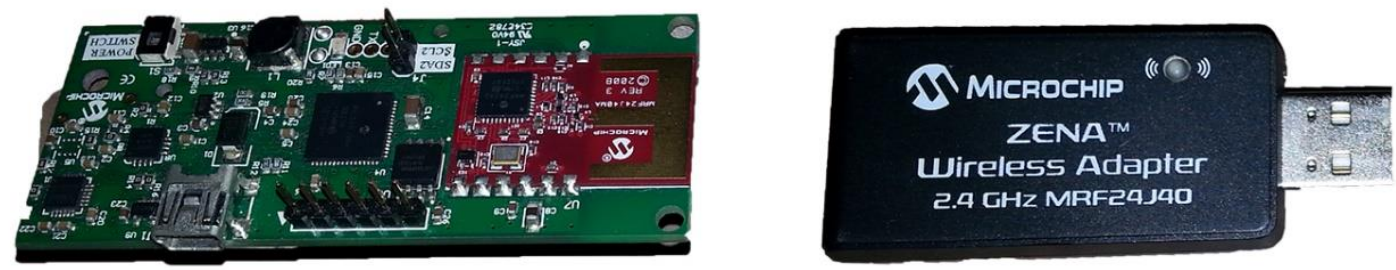

Figure 8: IMU Chipset and Receiver

\subsubsection{Quaternion Output}

Each IMU sensor provides a rotational value as output in the form of a quaternion. Upon start-up, the sensor creates its own reference frame by detecting gravity and mapping this as its z-axis (or up/down axis) [1][68]. This data is then matched to the coordinate system of the main Unity program. For more information on matching the reference frames and quaternion transformation, view the previous study [1].

Before each task of the program begins, the user must be sitting facing forward, with the elbow of their left arm bent at as close to a 90 degree angle as possible, as outlined in Figure 9: User Starting Position. This ensures that the coordinate system of the sensors can match the 
forward-facing axis of the main Unity program co-ordinate system (and in effect the robotic arm position) by applying an initial offset on start-up. The offset is created by averaging a range of quaternion readings on program start-up, and applying that difference to readings taken over the course of the task. This offset is created and applied at the beginning of every task to reduce sensor error, and thus the user must assume the starting position before each task begins. This also ensures that every participant begins each task of the experiment from the same position.

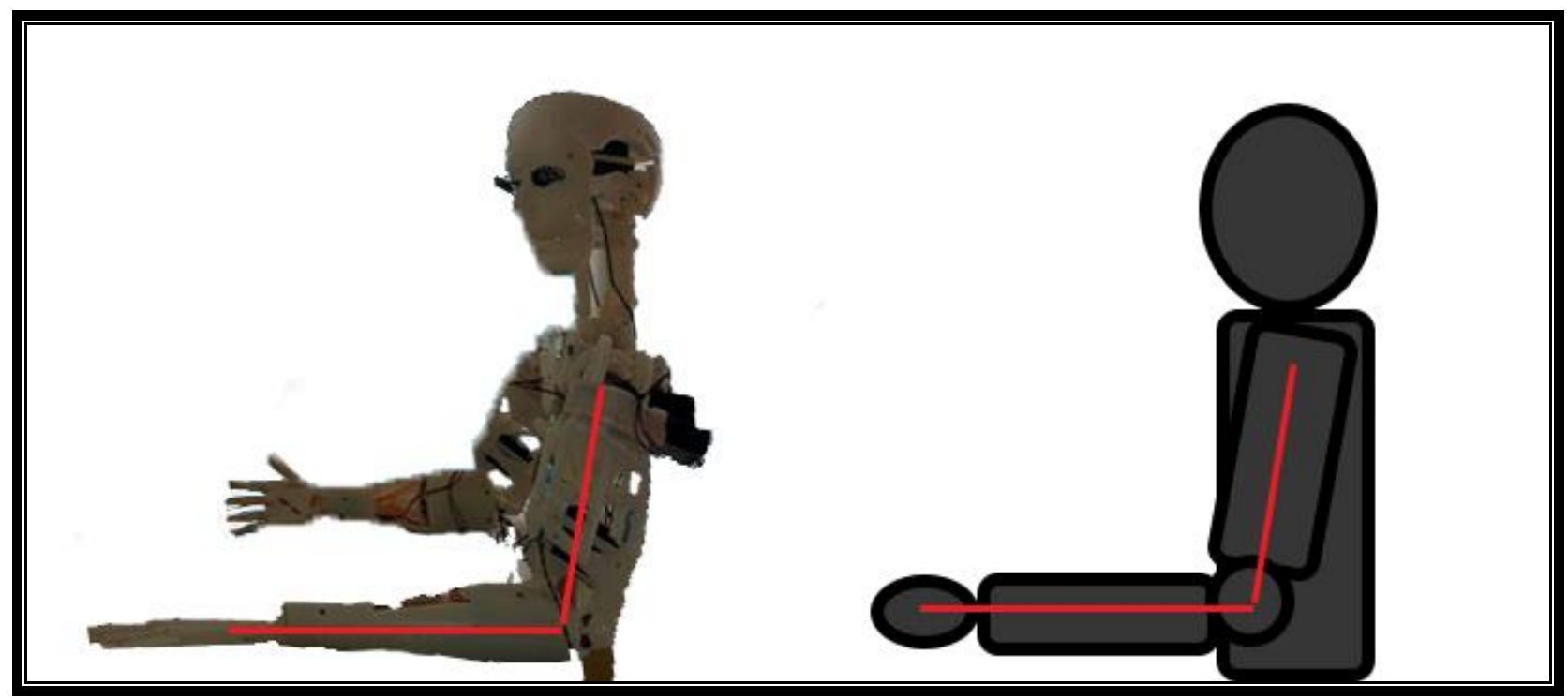

Figure 9: User Starting Position

Gimbal lock, a common concern in engineering that involves multi-axis rotations such as with robotic arm motion, is not a problem in our prototype. Our arm prototype has three points of rotation mapped to the data from the IMUs. Each rotation in the robotic arm utilizes one servo and thus each point only rotates on a single plane that is limited to less than 180 degrees of rotation and does not overlap any other rotation plane (see Figure 10: Robotic Planes of Rotation). These rotations were limited to prevent prototype breakage. Therefore, although we do use quaternion data from the IMU sensors, it can be safely converted to Euler rotation angles as we are only interested in one plane of rotation for each sensor for the purposes of this experiment. 


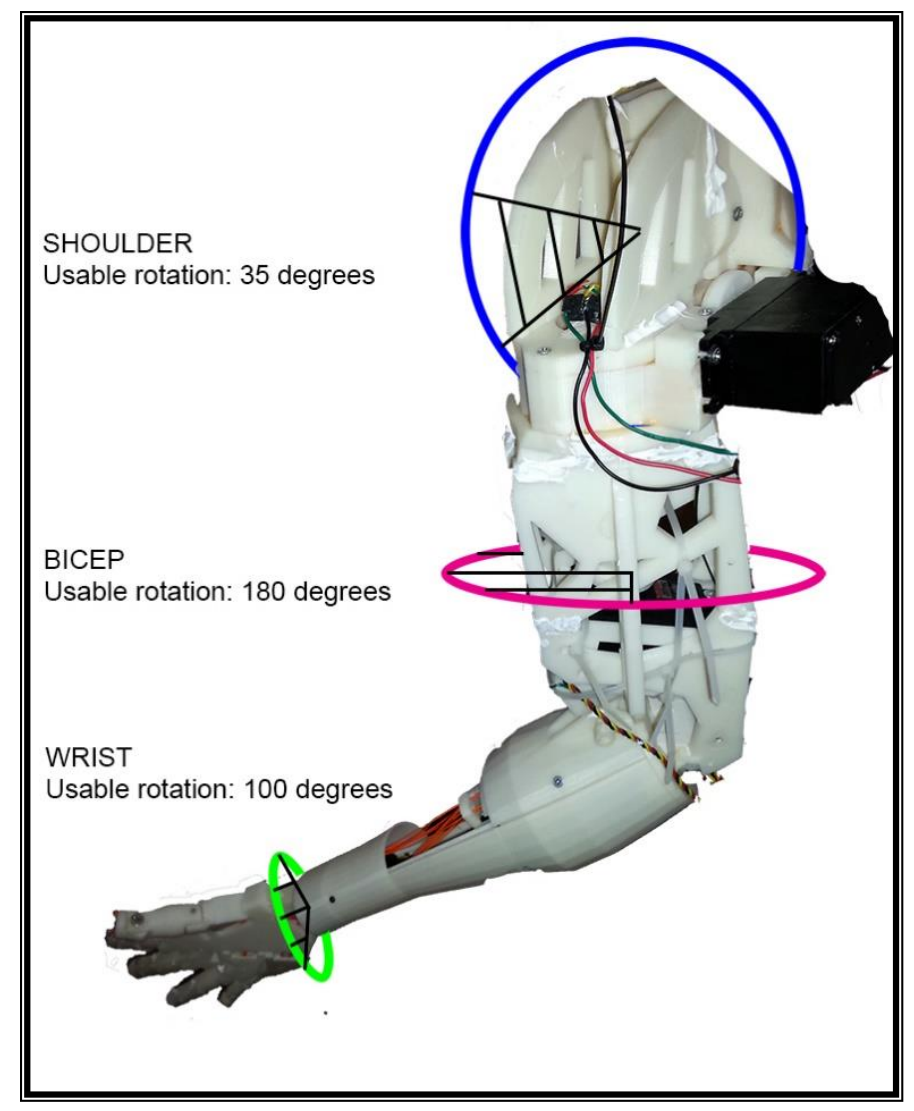

Figure 10: Robotic Planes of Rotation

A previous experiment using the same sensors employed in this study determined that in order to minimize unwanted noise and sensor drift, the sensors would need to remain motionless for a minimum of 13 seconds upon start-up [1]. It was estimated that with this particular IMU the 13 second wait time was the minimum amount of time needed for the sensor fusion algorithm to engage properly. It is unknown whether this issue was resolved as this specific sensor is no longer supported by the manufacturer.

\subsubsection{Haptic Jacket}

\subsubsection{Overview}

The haptic jacket, aside from being a convenient way to attach and immobilize the IMU sensors on the participant, also housed the wiring and vibration motors needed to provide haptic 
feedback. This feedback differs from other types of haptic feedback in robotics, in that it is used specifically as a signal to notify the participant when they were near or outside of the robot's range of motion, as opposed to attempting to recreate a feeling of holding or touching an object through force feedback

Using vibration motors as output, two styles of vibration feedback were designed. Vibration A style indicates a simple binary style, where the vibration is either at a constant, full strength or non-existent. Vibration B style indicates a vibration style where both the strength and frequency of the vibration is variable depending on user input.

Like the robot servo control, the vibration motors in the haptic jacket were also driven by an Arduino microcontroller sewn into the back of the jacket. The jacket then was directly connected to the experiment computer terminal via USB cable, which allowed for quick transfer of signals and data, as well as USB power. A wireless setup would be ideal for applications that involve more movement, but for the purposes of this experiment the participants were seated and thus a direct connection was preferred. This setup can be seen in Figure 11: Haptic Jacket

\section{Wiring.}




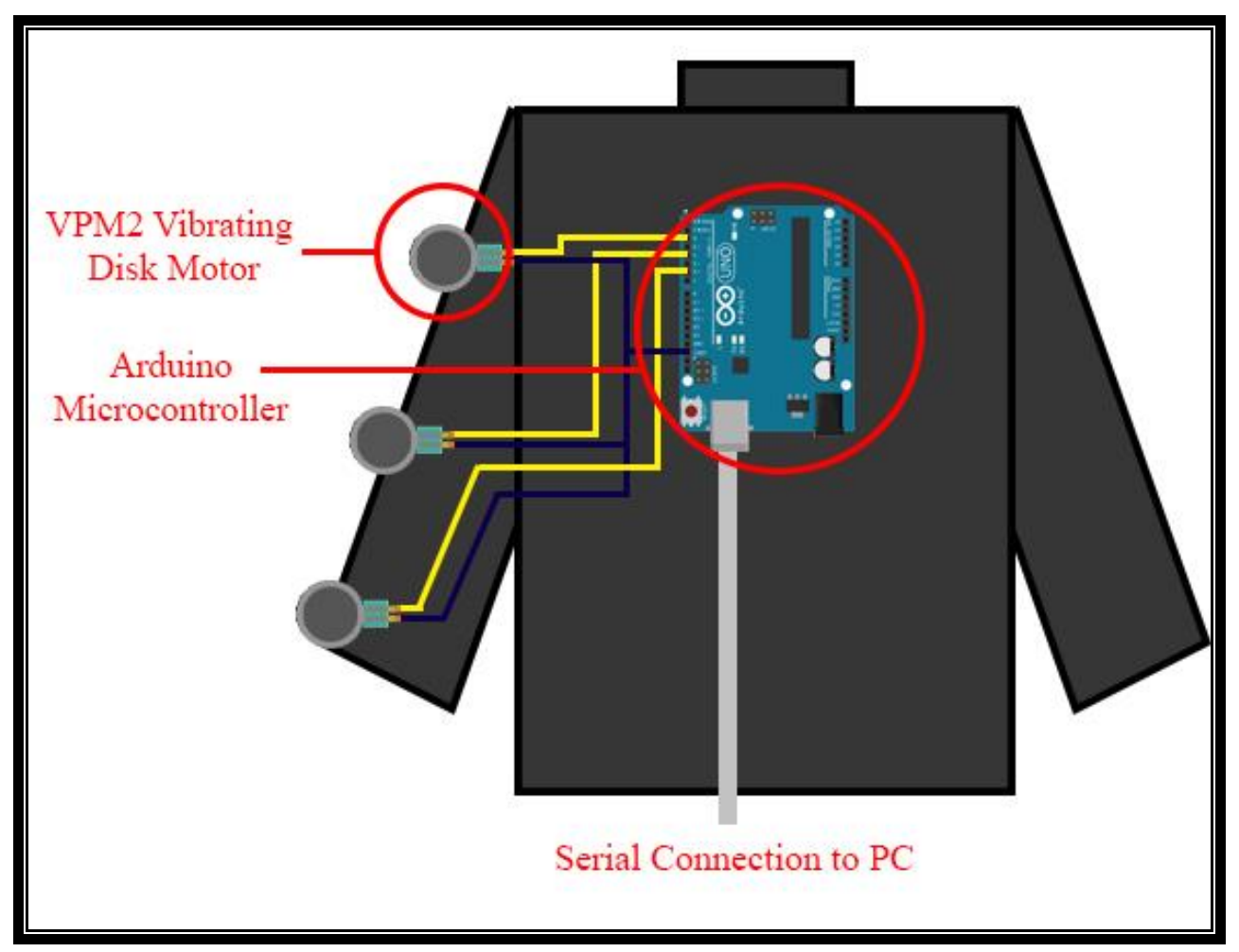

Figure 11: Haptic Jacket Wiring

\subsubsection{IMU housing}

In order to prevent shifting of the motion sensors on the body, plastic housings were 3D printed and attached securely to the jacket (see Figure 12: IMU Housing on Jacket). To prevent any further shifting, Velcro straps were also employed at the site of the 3D printed housings, and tightened while the participant was wearing the jacket. This ensured that the sensors would be able to read body movements as accurately as possible by preventing unwanted noise caused by the sensor moving over time. 


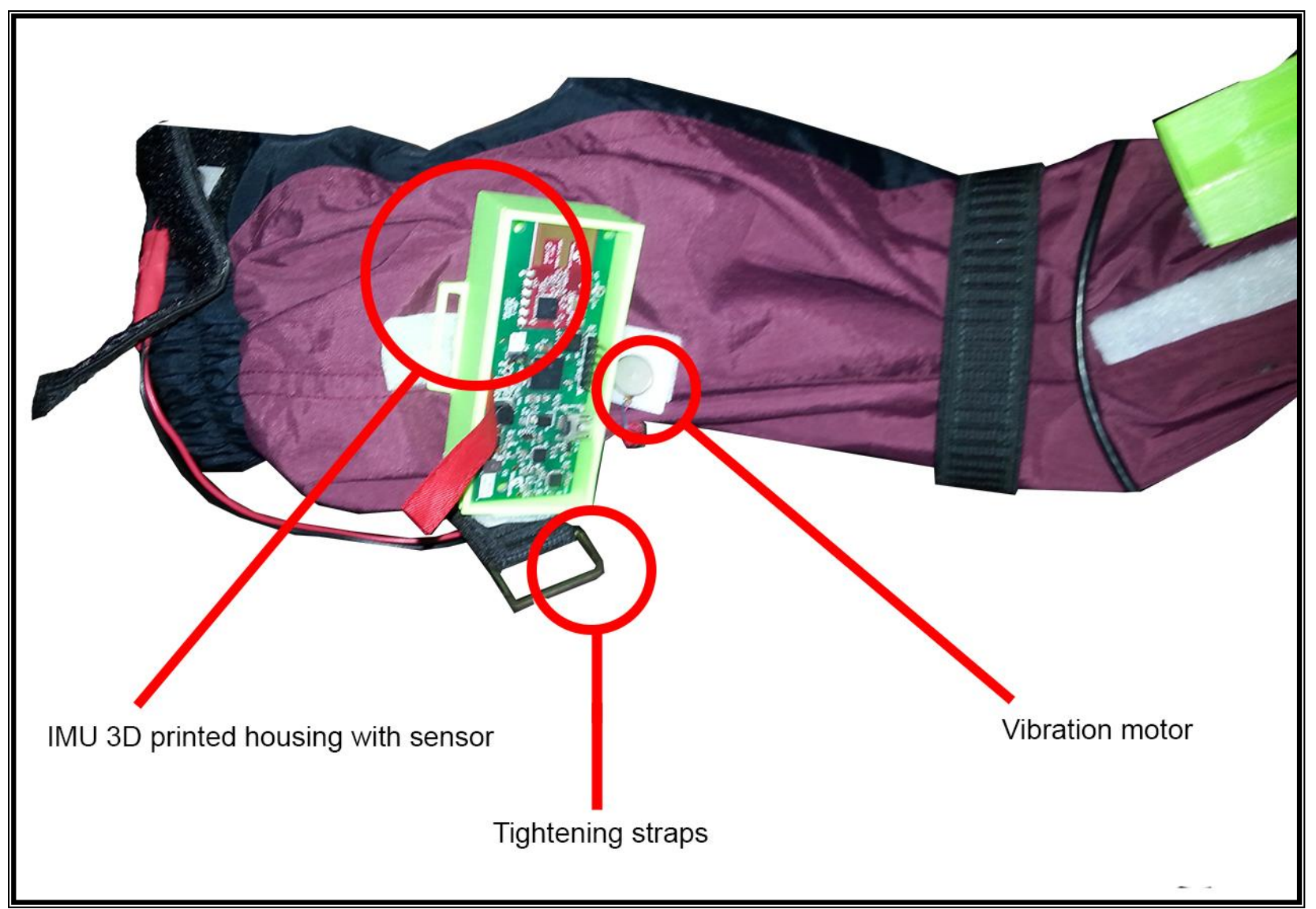

Figure 12: IMU Housing on Jacket

\subsubsection{Vibration Motors and Pulse Width Modulation}

The vibration motors were sewn into the haptic jacket at locations beside each sensor that they were meant to indicate. The motors were positioned at a suitable distance as to not interfere with the IMUs or cause any unwanted noise, while still being close enough to each sensor that it would be clear where the indication was coming from.

The type of motor used was the VPM2 Vibration disk motor, which has a maximum operating voltage of $3.5 \mathrm{~V}$ [45]. In order to change the voltage applied to the vibration motor by the Arduino (which supplies 5V by default), a pulse width modulation signal was used. Pulse width modulation is a technique where the full high $5 \mathrm{~V}$ signal is sent in rapid on-off succession to simulate the desired voltage output over time [44]. The formula for the vibration used can be seen as: 


$$
\mathrm{V}_{\mathrm{avg}}=\mathrm{V}_{\text {high }} * \mathrm{~F}
$$

Where $\mathrm{V}_{\text {avg }}$ is the desired voltage output, $\mathrm{V}_{\text {high }}$ is the voltage provided by the microcontroller, and $\mathrm{F}$ is the frequency of the on/off pulse.

For our purposes, we can calculate the range of frequencies using our desired output voltages for each motor: the operating range of 2.5-3.5 volts [45].

$$
\begin{aligned}
& \mathrm{V}_{\text {avg }}=\mathrm{V}_{\text {high }} * \mathrm{~F} \\
& 3.5=5 * \mathrm{~F} \\
& \mathrm{~F}=0.7 \\
& \text { and } \\
& \mathrm{V}_{\text {avg }}=\mathrm{V}_{\text {high }} * \mathrm{~F} \\
& 2.5=5 * \mathrm{~F} \\
& \mathrm{~F}=0.5
\end{aligned}
$$

Therefore, the range of possible on/off cycles we use in order to simulate our operating voltages ranges from $50 \%$ to $70 \%$ of one normal clock cycle. This range now represents the strength range of each motor that was possible. This allowed the strength of the vibration disk to be readily controlled by software and different vibration strengths to be varied by situation depending on the input of the participant.

\subsubsection{Flex Glove}

A glove was also fashioned to the haptic jacket in order to allow finger control. Due to the lack of robustness of the finger ligament design, the fingers had a simple binary state of open or closed. The flex glove was a simple work glove outfitted with a flex sensor that detected the angle of the user's fingers to detect an open or closed state.

\subsubsection{Oculus Rift Headset}

In order to give a first-person perspective, two high-definition webcams were mounted in the eye sockets of the robot. The webcam image was then sent to the display of an Oculus Rift Dev Kit 1 virtual reality headset. While the Oculus has mainly been used for virtual reality gaming in the past, it was used in this prototype to simulate perspective as if the user had the 
view of the robot. This design should allow the user to better judge the robot's components in 3D space.

\subsubsection{Software}

A Unity program was used as the highest level program running on the experiment terminal responsible for the direction of all of the components. The outline of the software hierarchy can be seen in Figure 13: Software Hierarchy. The choice to use Unity [62], an object-oriented 3D video game engine, was made for a number of reasons. The first reason is that Unity has 3D matrix mathematic functions built into the scripting language that made working with quaternion data much simpler than coding those functions by hand. As well, the previous study by Dennis Arsenault [1] had used the same IMU sensors within the Unity architecture, and the IMU framework of this study was based upon that previous framework. Finally, Unity was the easiest way to bring the Oculus headset into the prototype as well as deliver webcam images to the Oculus display, as Oculus has developed a Unity package for use with their headset [63], allowing for easy system integration. 


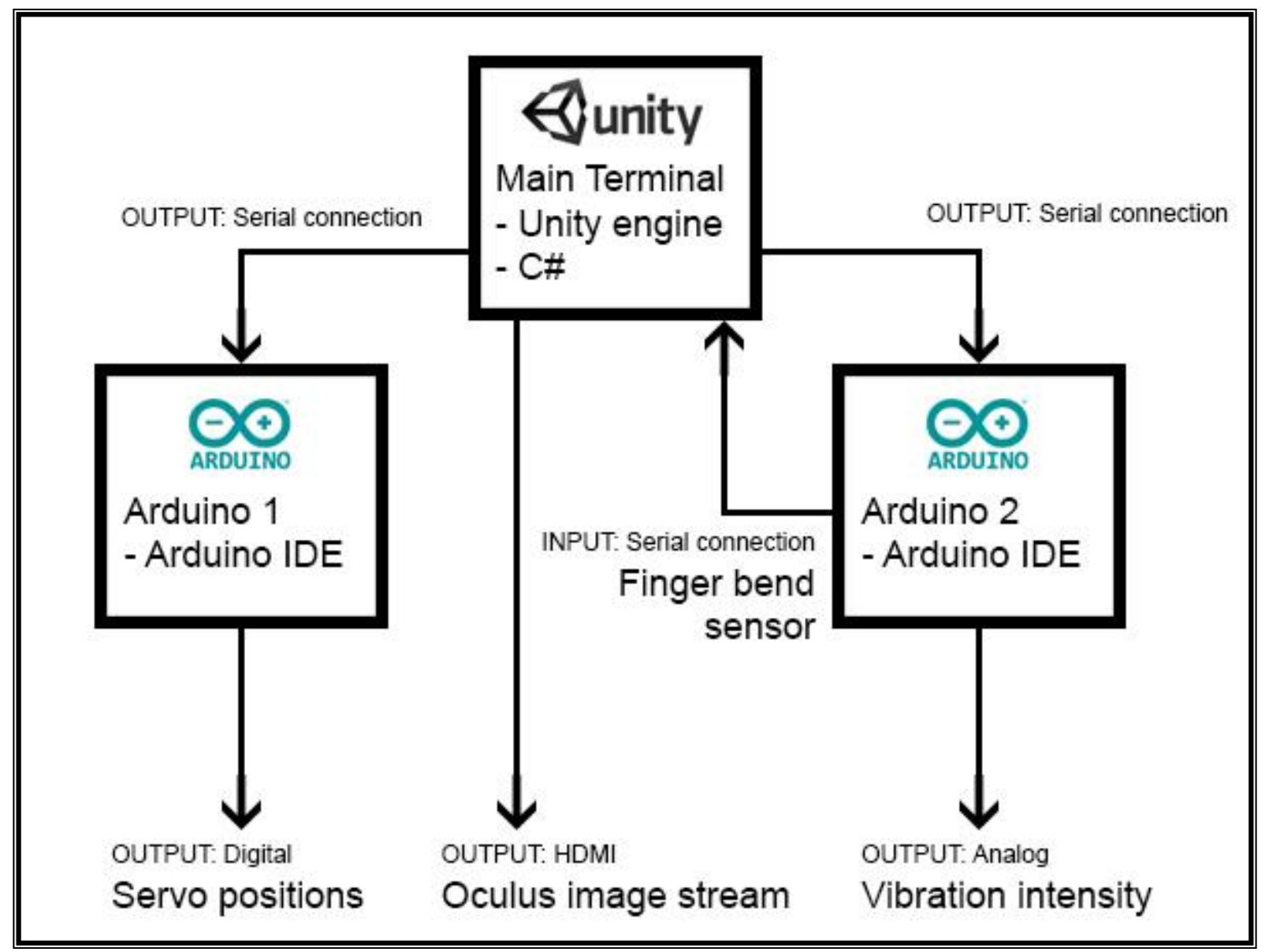

Figure 13: Software Hierarchy

Arduino microcontrollers directly controlled all of the physical components, namely the servo motion, vibration feedback and flex sensors. In this prototype they acted as an intermediary between the physical components and the main Unity program receiving quaternion data from the IMUs. The main Unity program interpreted the received quaternion data and sent an appropriate response command to the Arduino controlling the servo motors and the Arduino controlling the haptic feedback. 


\subsubsection{Device Limitations}

\subsubsection{Overview}

The device had some unavoidable limitations, both expected and unexpected. These limitations became apparent during the build process and during pilot tests, and the design of the experiment was adjusted to try and minimize these limitations affecting experiment results. Some limitations were unavoidable due to the small scope of this project, and would be good topics for future research.

\subsubsection{Servo Latency}

A major problem with the robot design is the difference in possible movement times between human arm motion and the robotic arm components. As we can see in Figure 14, which shows the average of ten trials for the robot joints to move 20 degrees in rotation, the further away from the controlling servo the point of rotation is, the longer it takes to move the part. In terms of human parts, this means the part corresponding to bicep rotation moves significantly slower than wrist rotation, which is almost instant. This is most likely due to the fact that as we move further from the tip of the hand the servo is required to move more weight. The shoulder servo also tends to move faster when rotating downwards as opposed to upwards due to the benefit of the force of gravity. 


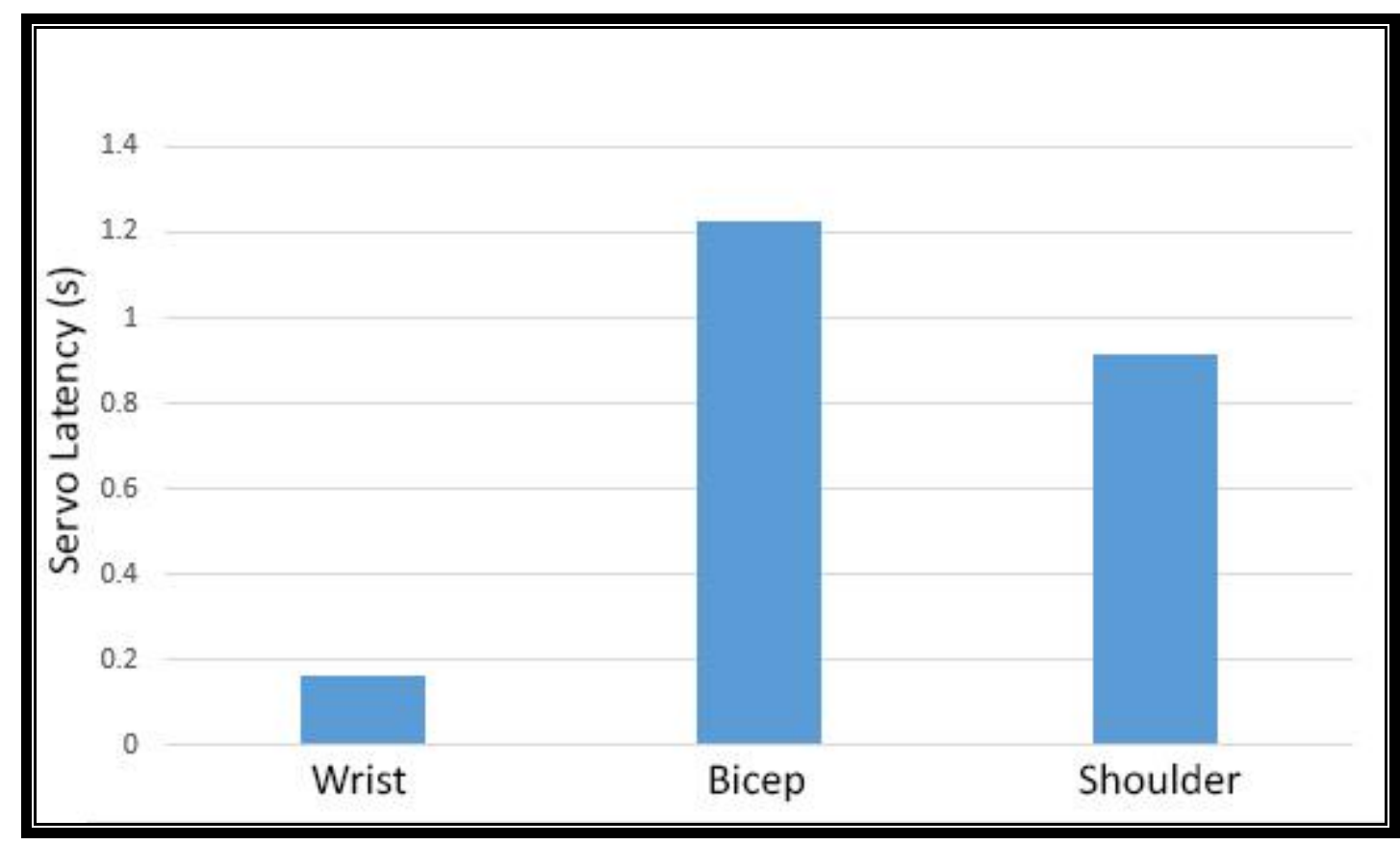

Figure 14: Servo Latency Times for 20 Degrees of Rotation

\subsubsection{Vibration Disconnect}

A secondary problem to the lag of robotic arm motion is the vibration not coinciding with that motion. By design, the vibration feedback is enabled when the user's arm leaves the possible range of motion of the robotic arm, which is monitored by the IMU sensors and not the actual robotic arm locations. The human motion could be completed much quicker than the robotic motion, and thus vibration feedback could happen while the robotic arm is still in motion leading to confusion. This also could lead to a mental disconnect between the user's body positioning and the robotic body positioning if the user did not use slow enough movements.

\subsubsection{Fixed Perspective}

Another product of the servo latency was the immobilization of the robot head, meaning the first-person perspective was fixed. The choice to fix the first-person perspective was made during pilot studies when it was found that robot head motion varied too much from user head motion due to the speed at which the head can turn, which resulted in self-reported feelings of motion sickness. It is possible that a fixed first-person perspective was a detriment to the user's 
depth perception, but in order to combat this the field of view was made such that the entire experiment area and robotic arm could be seen at all times. Also, the third person view was immobilized by having the user sit in one position behind the robot without moving around the experiment area, for a more fair comparison in perspective.

\subsubsection{Breakage}

A significant problem with the prototype was part breakage. Due to the limit in size that a part could be 3D printed, the build consisted of many small parts which lead to many break points. For this reason another method or design in building the robot framework is suggested.

It is possible that a metal frame may have been more stable however the weight of the arm would have increased significantly and a more powerful servo motor and gearbox system would need to be designed to allow locomotion. It would also drive up costs, so this option was not explored.

\subsubsection{Body Shape Differences}

A number of users noted on the post-study questionnaire that a better-fitting jacket would be beneficial. It is possible that shorter limb length and finger length may have had an effect on the ease of use of the prototype as only one size of jacket was created, but this was not explored in any meaningful way.

\subsection{Experiment}

\subsubsection{Overview}

The study involved one scheduled 60-minute session per participant, including time to fill out a questionnaire at the end of the session. Testing involved a total of eight tasks to be completed by the participant with different combinations of variables for each task. The session can be broken down into two main blocks of tasks, involving completing four tasks with and without the Oculus Rift (OR) virtual reality headset to obtain the first-person and third-person 
perspectives of the robot. As well, each task needed to be completed using both of the different types of haptic feedback. The two tasks that needed to be performed with all combinations of these variables involved using the motion controllers to objectively move the robot arm with both a gross motor movement task and a fine motor movement task. The various combinations are outlined in Table 1: Task Outline.

\begin{tabular}{|c|c|c|}
\hline & Vibration A & Vibration B \\
\hline $3^{\text {rd }}$ Person View & 1 Fine motor task and & 1 Fine motor task and \\
(without Oculus) & 1 Gross motor task & 1 Gross motor task \\
\hline $\begin{array}{c}\mathbf{1}^{\text {st }} \text { Person View } \\
\text { (with Oculus) }\end{array}$ & 1 Fine motor task and & 1 Fine motor task and \\
1 Gross motor task & 1 Gross motor task \\
\hline
\end{tabular}

Table 1: Task Outline

Task time completion was used as the main method of measuring usability by comparing the time it took participants to complete each task under the various testing conditions. By comparing each participant to themselves, the overall task time is not as important as the differences between tasks with different variables for each individual participant, and can give us a clear picture of each variable's effect on the usability of the system.

When any portion of the robot arm has reached its limit of range, haptic feedback in the form of vibration was relayed back to the user to signify this limit. This vibration is the same vibration technology that is found in modern cell phones, and should be familiar to most participants.

After the 8 motor tasks were complete, the participants were asked to complete a questionnaire regarding the tasks completed and devices used in the session, as well as provide their preferences and opinions about the prototype and technology. The goal of the study was to examine the usability of the motion controllers, to determine if there was a difference in usability when using the Oculus headset, and to determine if one style of vibration feedback was a more effective form of vibration for notifying the participant about the range restrictions of the robot. 


\subsubsection{Perspective}

The main hypothesis of this study was that a first-person perspective would be more beneficial and intuitive in controlling a telepresence robot using real-world movements for fine motor tasks than a third-person perspective. In order to examine this hypothesis, a facet of the experiment needed to show empirical differences between tasks with and without the Oculus Rift head-mounted display in use, as well as participants' self-reported preferences. The two perspectives used can be seen in Figure 15: Perspective Difference.

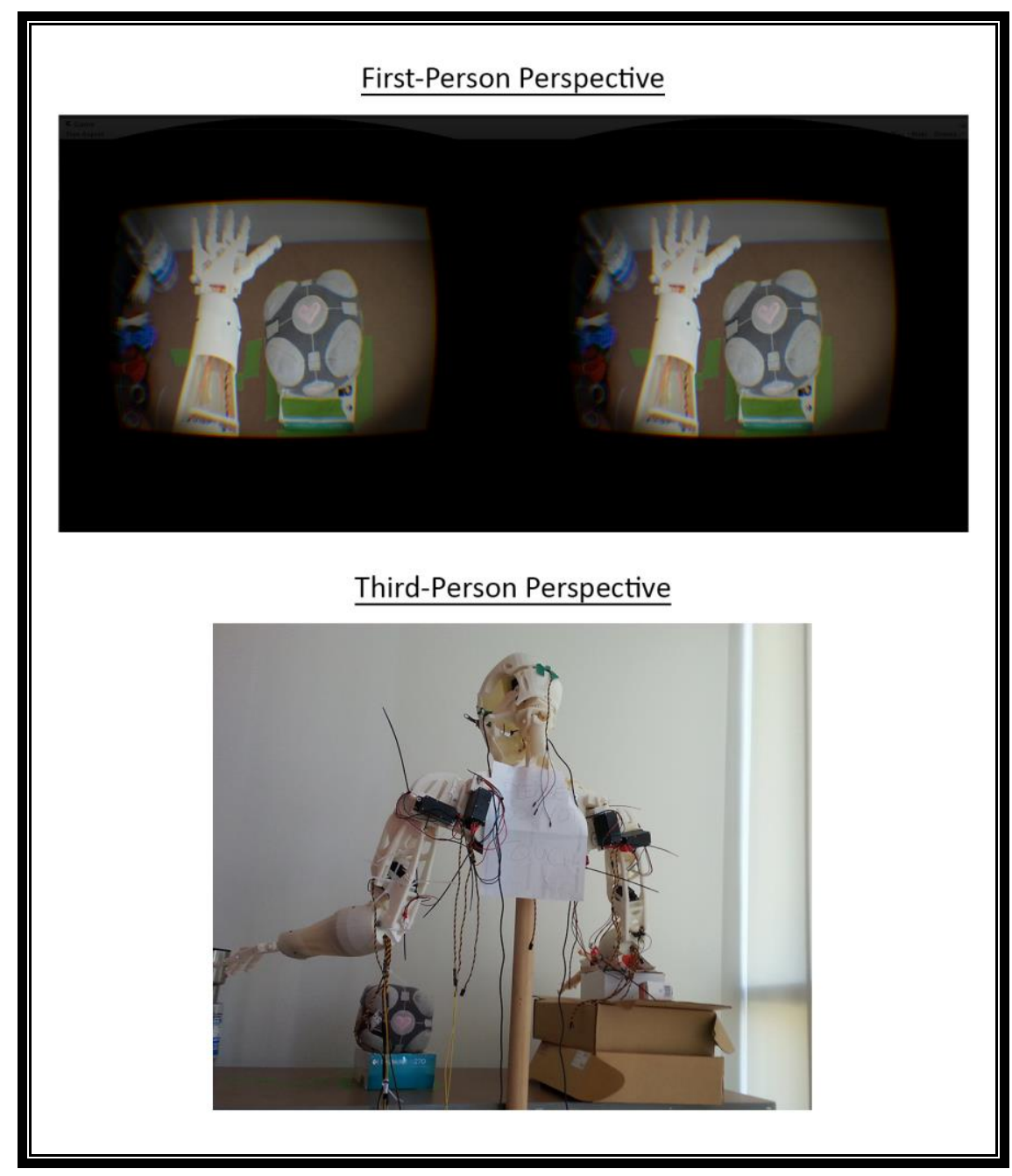

Figure 15: Perspective Difference 


\subsubsection{Haptic Feedback}

A secondary facet to the study was to determine if haptic feedback in the form of vibration would be useful in a prototype such as this in order to notify the participants when they had reached the limits of the robot. In order to test this hypothesis, each task was completed for two different vibration styles. Vibration style A was a binary style, in that it was fully on when the participant went out of range on that particular motion sensor, and completely off when inside the robot's range of motion. Vibration style B was a strength style vibration that corresponded with how close the participant was to the invisible boundary indicating the end of the robot's range of motion (meaning it ramped up the strength values of the vibration depending on the number of degrees away from that boundary).

\subsubsection{Tasks}

Each of the eight tasks performed by the participants had one of two objectives. The first task, named the gross motor task, involved moving the whole robotic arm in whatever way was easiest for the participant in order to move a $6 \times 6 \times 6$ inch cube off of a raised platform, as seen in Figure 16: Gross Motor Task. The task was considered complete once the cube was entirely off of the platform area, with no part of the cube touching the platform. This task was designed to require larger, less accurate movements when compared to the second task.

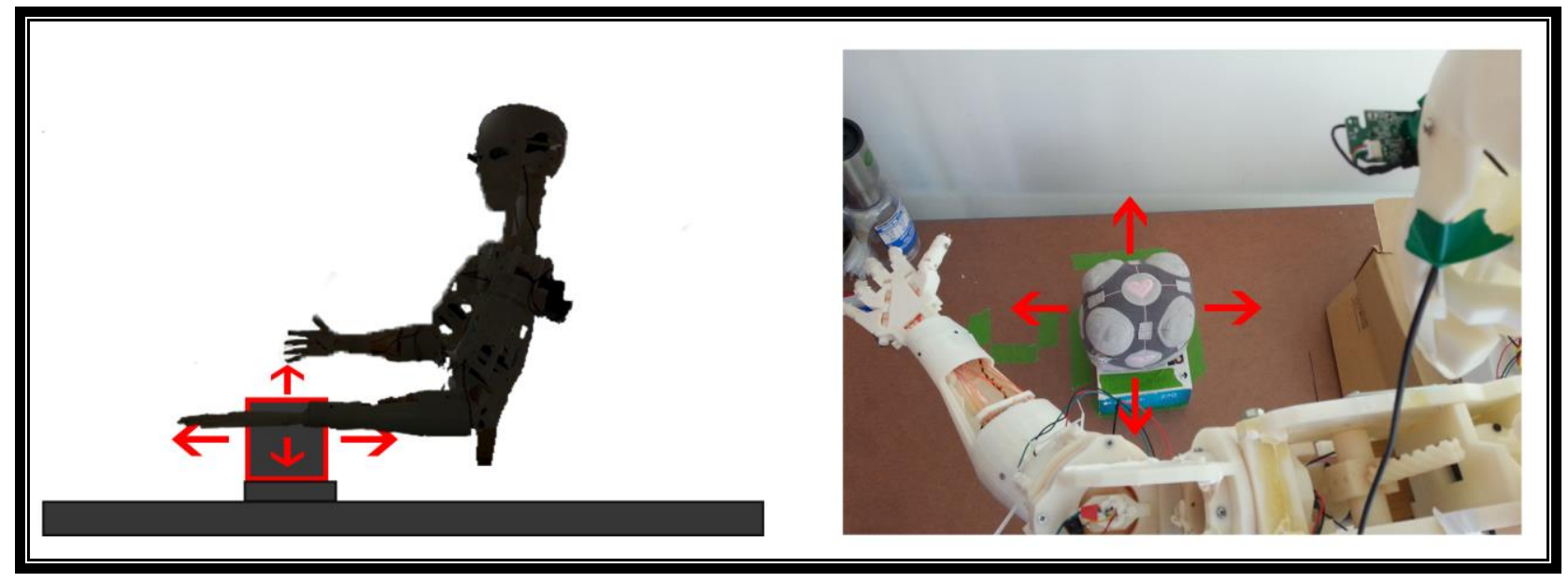

Figure 16: Gross Motor Task 
The second task objective, named the fine motor task, involved grasping a mug by its handle on a raised platform without knocking the mug off, as seen in Figure 17: Fine Motor Task. Due to prototype strength limitations, and in order to reduce strain on the prototype, the participant was not required to lift the mug but instead the task was considered complete if the participant could position at least one finger around the handle as if they were about to lift the mug. This task required a finer control of the prototype than the gross motor task in order to position the robot fingers within the handle.

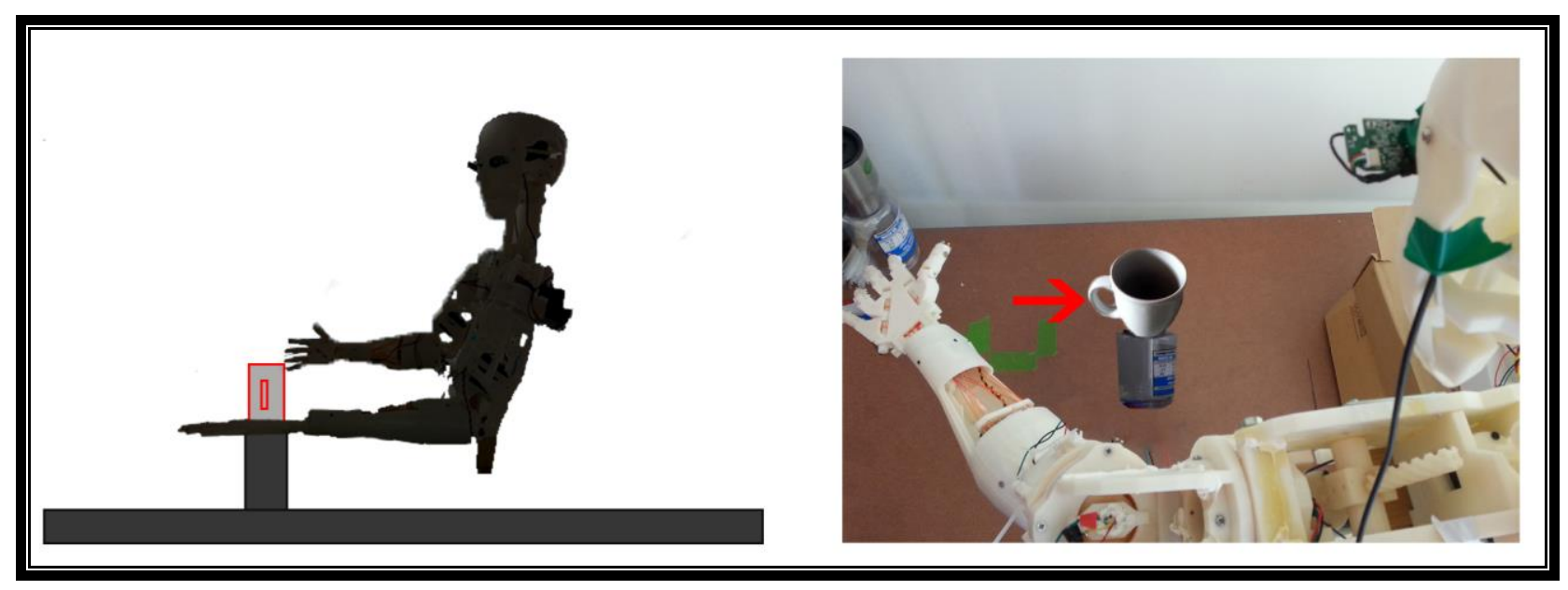

Figure 17: Fine Motor Task

Both of these tasks were repeated four times in order to test the different variables of perspective (with or without the head-mounted display) and haptic feedback (different styles of vibration) as outlined in Table 1: Task Outline. A maximum time of five minutes was allotted for each task before it would be considered a failure. None of the participants reached the maximum cut-off time for any task, meaning all participants were able to complete all tasks.

\subsubsection{Procedure}

The specific procedure of the experiment was as follows: 
1. Participants were asked to read and sign the waiver as per university ethics regulations (see Appendix A).

2. The researcher then gave an oral background of the project, making sure to cover the points outlined in the pre-experiment script (see Appendix E). This was to introduce the experiment and all of its elements as well as all of the components of the device, and allow the participant to voice any questions or concerns prior to the commencement of the experiment. This was also to ensure that the participant understood the written waiver and to reiterate the key points of the waiver regarding privacy and the option to terminate the experiment at any time if they were uncomfortable for any reason. None of the participants reported any discomfort or declined participation once the study began.

3. The researcher then used a random number generator to determine the order of the tasks. This was to mitigate any learning effect that might interfere with final results. The order of tasks was then noted in the log file so that it could be later referenced.

4. The participant then sat in a chair directly behind the robot at a distance of four feet. The researcher aided the participant in putting on the haptic jacket and flex glove, if needed.

5. The researcher inserted the batteries into the IMUs, and after waiting the appropriate amount of time to prevent sensor drift (see Section 3.1.3.2), attached the sensors to the participant. It is important to complete this step as close to actual testing as possible in order to prevent unwanted sensor drift.

6. The video recorder was enabled at this time.

7. Following the task order determined earlier, the researcher then reiterated the objective of the current task as well as the type of vibration the participant should expect.

8. The participant was instructed to move to the starting position and the program was started. The participant then completed the laid out task without further instruction from the researcher.

9. After task completion, the IMUs were reset, again to counteract sensor drift. During this time the researcher asked the participant if they felt any discomfort, and ensured they were willing to continue. This is especially important after tasks involving the Oculus HMD, due to the potential for VR Sickness (as discussed in Section 2.5).

10. Steps 7 and 8 were repeated until all tasks were completed by the participant. 
11. Following the final task, the researcher helped the participant remove the testing equipment, and directed them to complete the post-study questionnaire (see Appendix C). The video recorder was turned off at this time.

12. The completed questionnaire was immediately locked in a filing cabinet in the lab. Before departure the researcher asked the participant if they had any closing questions or comments about the study. 


\section{Chapter: Results}

\subsection{Overview}

A sample of 30 individuals completed the study, with ages ranging from 19 to 53 . Every participant completed all of the eight tasks outlined in the experiment without fail, and completed the questionnaire (Appendix C) asking them to self-report on their experiences with the device. The majority of these individuals were from the Carleton community due to the recruiting procedures, which included posters around the campus and mailing lists (see Appendix B). No exclusive criteria were required in order to participate, aside from the participant being physically able to move their left arm in a meaningful way to perform everyday tasks.

\subsection{Data Analysis}

\subsubsection{Differences in statistical groups}

Several statistical groups were self-identified in the post-questionnaire. Out of 30 participants, 17 were male, 13 female, with 23 participants being right-handed. Ages ranged from 19 to 53. Of those thirty participants, 23 reported having previous experience with motion controllers such as the Wii [64], Kinect [30] or motion-controlled cell phone applications, with 13 of those 23 reporting a good amount of experience.

\subsubsection{Age}

As we can see in Figure 18: Participant Age Distribution, the majority of respondents fell into the range of 20-30 years of age. Due to the small sample of ages in other ranges, it is difficult to perform a meaningful age comparison. 


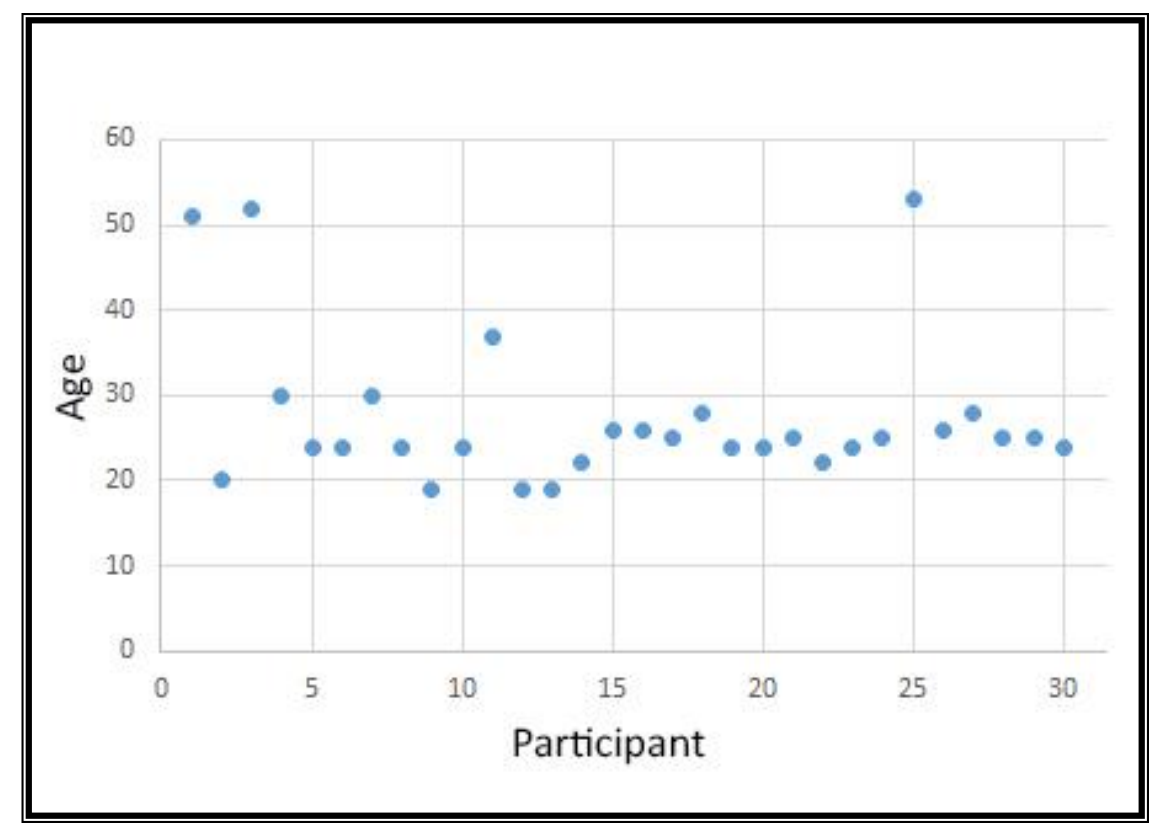

Figure 18: Participant Age Distribution

\subsubsection{Experience}

Although there is a large disparity in sample size between those who self-report having experience with motion controllers $(n=23)$ and those who are on the opposite scale $(n=6)$, there is not a large difference when comparing the means between these two groups. The experienced group did have slightly lower mean times with a total task average of 26.77 seconds versus 29.40 seconds for the less experienced group. However, we cannot call this a significant finding as the sample difference is too large. The mean times for each group can be seen in Table 2. 


\begin{tabular}{|c|c|c|c|c|c|c|c|}
\hline & $\begin{array}{c}3^{\text {rd }} \text {-person } \\
\text { tasks }\end{array}$ & $\begin{array}{c}\mathbf{1}^{\text {st }} \text {-person } \\
\text { tasks }\end{array}$ & $\begin{array}{c}\text { Gross } \\
\text { motor } \\
\text { tasks }\end{array}$ & $\begin{array}{c}\text { Fine } \\
\text { motor } \\
\text { tasks }\end{array}$ & $\begin{array}{c}\text { Vibration } \\
\text { A tasks }\end{array}$ & $\begin{array}{c}\text { Vibration } \\
\text { B tasks }\end{array}$ & $\begin{array}{c}\text { Total task } \\
\text { average }\end{array}$ \\
\hline $\begin{array}{c}\text { Experienced } \\
\text { User }\end{array}$ & 25.92 & 27.61 & 28.30 & 25.24 & 28.16 & 25.38 & 26.77 \\
\hline $\begin{array}{c}\text { Inexperienced } \\
\text { User }\end{array}$ & 29.86 & 27.24 & 25.72 & 34.23 & 30.82 & 29.97 & 29.40 \\
\hline
\end{tabular}

Table 2: Mean Task Completion Times Based On User Experience

All variables were compared between the two groups but no significant differences were found, as shown in Table 3 below:

\begin{tabular}{|c|c|c|c|}
\hline Comparison & t-value & p-value & Significance (p<.05) \\
\hline Total Task Times & 0.5908 & 0.5595 & No \\
\hline $\begin{array}{c}\text { Total Task Times } \\
\text { without First Task }\end{array}$ & 0.7775 & 0.4436 & No \\
\hline $\begin{array}{c}\text { Gross vs. Fine } \\
\text { Motor Task }\end{array}$ & -1.5667 & 0.1288 & No \\
\hline $\begin{array}{c}\text { With vs. Without } \\
\text { Oculus Rift }\end{array}$ & 0.7777 & 0.4435 & No \\
\hline $\begin{array}{c}\text { Vibration A vs. } \\
\text { Vibration B }\end{array}$ & -0.4354 & 0.6667 & \\
\hline
\end{tabular}

Table 3: Individual Variable Comparison between Experienced and Non-Experienced Users

It is worth commenting on the significance value of gross vs. fine motor task comparison, which is approaching a significant value. Although it is not significant in this instance, this 
suggests that further research might find a significant value if a larger sample was used or confounding factors were minimized. If this value were found to be significant, this would suggest that those participants with experience using motion controllers have an easier time completing fine motor tasks than those without prior experience.

\subsubsection{Handedness}

It is possible that by restricting the participants to use only their left hand that some participants may have been hindered by being forced to use a non-dominant hand. The amount of right-handed participants outnumbered the amount of left-handed participants in our study on a count of 23 to 6 . Statistical t-tests were run to examine any difference between the two groups, but due to the difference in sample size, we cannot speak to their actual significance. We can see the comparison of mean times in Table 4.

\begin{tabular}{|c|c|c|c|c|c|c|c|}
\hline & $\begin{array}{c}\mathbf{3}^{\text {rd-person }} \\
\text { tasks }\end{array}$ & $\begin{array}{c}\mathbf{1}^{\text {st }} \text {-person } \\
\text { tasks }\end{array}$ & $\begin{array}{c}\text { Gross } \\
\text { motor } \\
\text { tasks }\end{array}$ & $\begin{array}{c}\text { Fine } \\
\text { motor } \\
\text { tasks }\end{array}$ & $\begin{array}{c}\text { Vibration } \\
\text { A tasks }\end{array}$ & $\begin{array}{c}\text { Vibration } \\
\text { B tasks }\end{array}$ & $\begin{array}{c}\text { Total task } \\
\text { average }\end{array}$ \\
\hline $\begin{array}{c}\text { Right-Handed } \\
\text { User }\end{array}$ & 26.97 & 28.58 & 27.51 & 28.04 & 28.82 & 26.74 & 27.78 \\
\hline $\begin{array}{c}\text { Left-Handed } \\
\text { User }\end{array}$ & 24.37 & 24.60 & 28.56 & 23.26 & 28.39 & 24.28 & 25.34 \\
\hline
\end{tabular}

Table 4: Mean Task Completion Times Based On Dominant Hand

All variables were compared between the two groups but no significant differences were found, as shown in Table 5 below. 


\begin{tabular}{|c|c|c|c|}
\hline Comparison & t-value & p-value & Significance (p<.05) \\
\hline Total Task Times & 0.5454 & 0.5899 & No \\
\hline $\begin{array}{c}\text { Total Task Times } \\
\text { without First Task }\end{array}$ & 1.0233 & 0.3153 & No \\
\hline $\begin{array}{c}\text { Gross vs. Fine } \\
\text { Motor Task }\end{array}$ & -0.7644 & 0.4513 & No \\
\hline $\begin{array}{c}\text { With vs. Without } \\
\text { Oculus Rift }\end{array}$ & -0.2495 & 0.8049 & No \\
\hline $\begin{array}{c}\text { Vibration A vs. } \\
\text { Vibration B }\end{array}$ & -0.4476 & 0.6580 & \\
\hline
\end{tabular}

Table 5: Individual Variable Comparison between Left and Right-handed Users

We can assume by this insignificance that our task objectives were general enough that participants were comfortable completing them with either hand, be it dominant or not (such as reaching or grabbing tasks). Perhaps different tasks would evoke a greater difference between the two groups, such as more complicated tasks such as writing or fine manipulation.

\subsubsection{Perspective}

To reiterate the first hypothesis: this experiment was designed in order to determine if perspective differences had an observable effect on the usability of a physical avatar in the form of a telepresence robot prototype. More specifically, it was hypothesized that a first-person perspective would be determined to have statistically lower timing data on the completion of the fine motor task when compared to a third-person perspective of that same task.

Using a within-subjects t-test, it was determined that there was not a significant difference between the timing data of a first-person perspective versus a third-person perspective. When examining the fine motor tasks specifically (see Figure 19: Individual 
Perspective Differences in Fine Motor Tasks), we get a t-value of 0.505301721 and a p-value of 0.617167 at $p<.05$, clearly not a significant result. In terms of the specific task examined here, our hypothesis can be disputed. It is possible that this result is due to the small sample size of this study $(\mathrm{n}=30)$, and that the large variability in individual differences is not able to be kept separate from our analysis at this size. Perhaps it may also be attributable the fact that we chose to use the left arm/hand for the experiment and the vast majority of the population is right hand dominant, although our analysis did not find a significant difference in task completion times between the two groups.

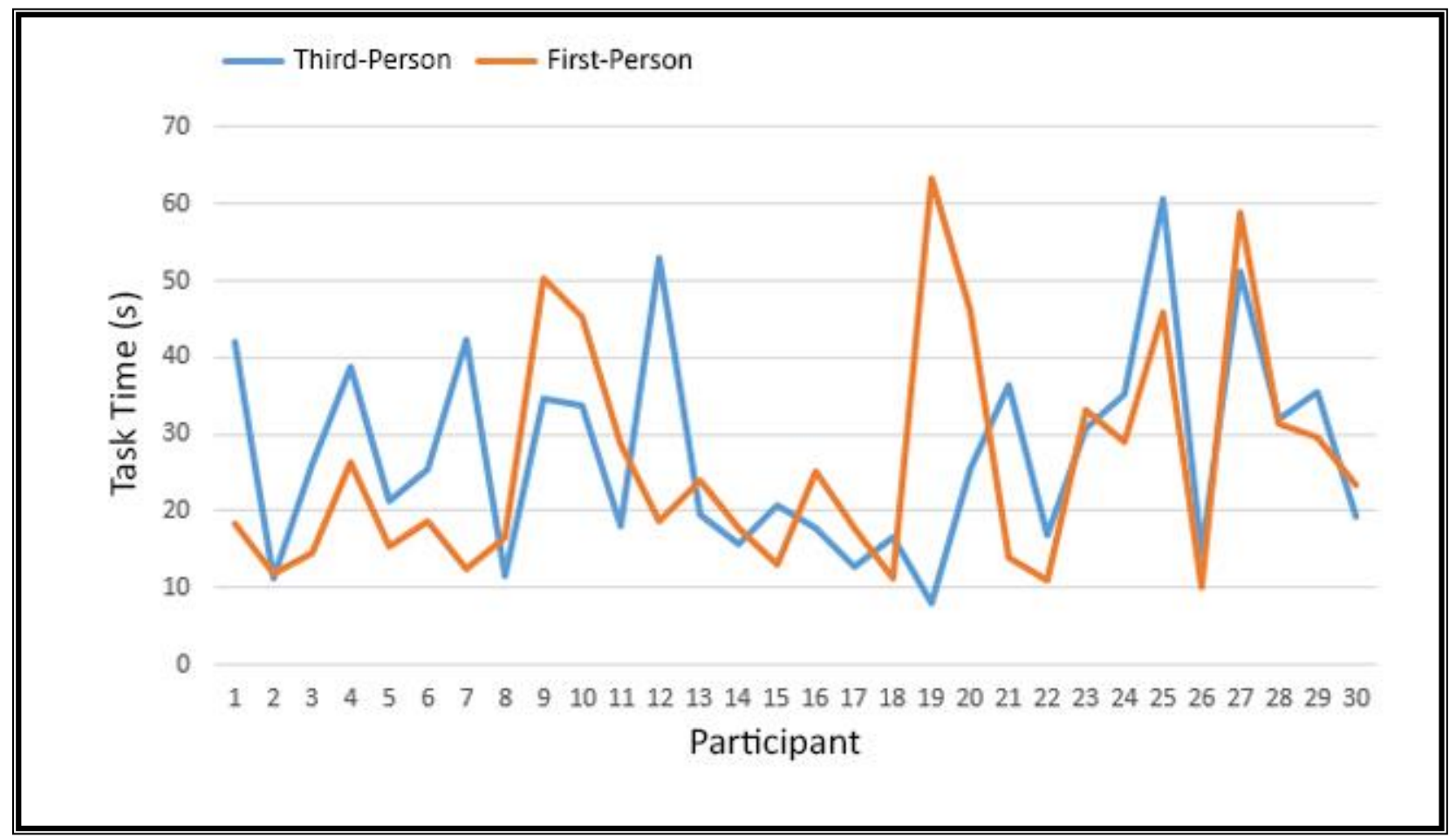

Figure 19: Individual Perspective Differences in Fine Motor Tasks

If we compare the average gross motor tasks in the same vein, we obtain a similar result (t-value of -0.816134797 , $p$-value of 0.421076529 , not significant at $\mathrm{p}<.05$ ). It would seem that perspective, in the way we have defined it, did not have a statistically observable difference on 
task completion times in this study. To see the comparison for individual task variables, see Table 6.

\begin{tabular}{|c|c|c|c|}
\hline Task & t-value & p-value & Significance \\
\hline $\begin{array}{c}\mathbf{1}^{\text {st }} \text { vs 3 } 3^{\text {rd }} \text { person with } \\
\text { Gross Motor Task } \\
\text { and Vibration A }\end{array}$ & -0.8224 & 0.4176 & No \\
\hline $\begin{array}{c}\mathbf{1}^{\text {st }} \text { vs 3 } \\
\text { Gross Morson with } \\
\text { and Vibration B }\end{array}$ & -0.1023 & 0.9192 & No \\
\hline $\begin{array}{c}\mathbf{1}^{\text {st }} \text { vs 3 } 3^{\text {rd }} \text { person with } \\
\text { Fine Motor Task } \\
\text { and Vibration A }\end{array}$ & 1.3647 & 0.1828 & No \\
\hline $\begin{array}{c}\mathbf{1}^{\text {st }} \text { vs 3 } \\
\text { Fine Motorson with } \\
\text { and Vibration B }\end{array}$ & & & No \\
\hline
\end{tabular}

Table 6: Perspective Comparison of Individual Task Completion Times

\subsubsection{Haptic Feedback}

The second hypothesis introduced two types of haptic feedback: Vibration A, a type of vibration that is switched on as soon as the user leaves the safe range-of-motion, and Vibration B, a type of vibration that increases in intensity as the user nears the boundary of that range. It was hypothesized that Vibration A would be a more effective form, as it would be easier for the user to recognize this type.

To analyze the second hypothesis, task timing data can be compared in the same way as it was for perspective differences. Using a within-subjects t-test, the mean time of all tasks completed with Vibration A was compared to all tasks completed with Vibration B, and was 
found to be not significant at $\mathrm{p}<.05$ ( $\mathrm{t}$-value of 1.652456473, $\mathrm{p}$-value of 0.109241 ). However, this value is approaching significance, and should not be disregarded completely.

If we compare individual tasks we will see a similar result as shown in Table 7:

\begin{tabular}{|c|c|c|c|}
\hline Task & t-value & p-value & Significance \\
\hline $\begin{array}{c}\text { Vibration A vs. B } \\
\text { with }\end{array}$ & 1.3013 & 0.2034 & No \\
Gross Motor Task & & & \\
\hline $\begin{array}{c}\text { Vibration A vs. B } \\
\text { with }\end{array}$ & 1.8769 & 0.0706 & No \\
$\begin{array}{c}\text { Gross Motor Task } \\
\text { With Oculus }\end{array}$ & & & No \\
\hline $\begin{array}{c}\text { Vibration A vs. B } \\
\text { with }\end{array}$ & 0.2265 & 0.8224 & \\
Fine Motor Task \\
Without Oculus
\end{tabular}

Table 7: Vibration Comparison of Individual Task Completion Times

As we can see, it is difficult to find a significant observable difference in the effect vibration style has on task performance. The closest value to significance (and in fact could be considered significant with rounding) is with the $1^{\text {st }}$ person perspective completing the fine motor task (t-value of $-2.000623429 \mathrm{p}$-value of 0.05487268 ). The value for the gross motor task is also approaching significance under the same conditions (t-value of $1.876909188 \mathrm{p}$-value of 
0.070624863). This suggests that Vibration A, the binary vibration style, is more effective at providing feedback for fine motor tasks when the participant is wearing the Oculus Rift headset in the first-person perspective. Perhaps this indicates that Vibration A is easier to interpret when the user cannot observe his or her own arm position due to the binary simplicity of the feedback (there is no range of strength to judge, only ON or OFF). When asked for a preference on the post-questionnaire, more users reported a preference for Vibration A, which will be discussed in more detail in Section 4.2.5: Self-reported results.

\subsubsection{Task Learning}

Carry-over effects are a possible weakness of within-subject experiments like this one [55]. The prototype was designed with the intention that it would be intuitive enough for any person, technical or non-technical, to use effectively on the first try. In order to determine if any learning or practice effect was present when using the device, the first random task completed by each participant was noted (see Figure 20: First Task vs. Average of Subsequent Tasks).

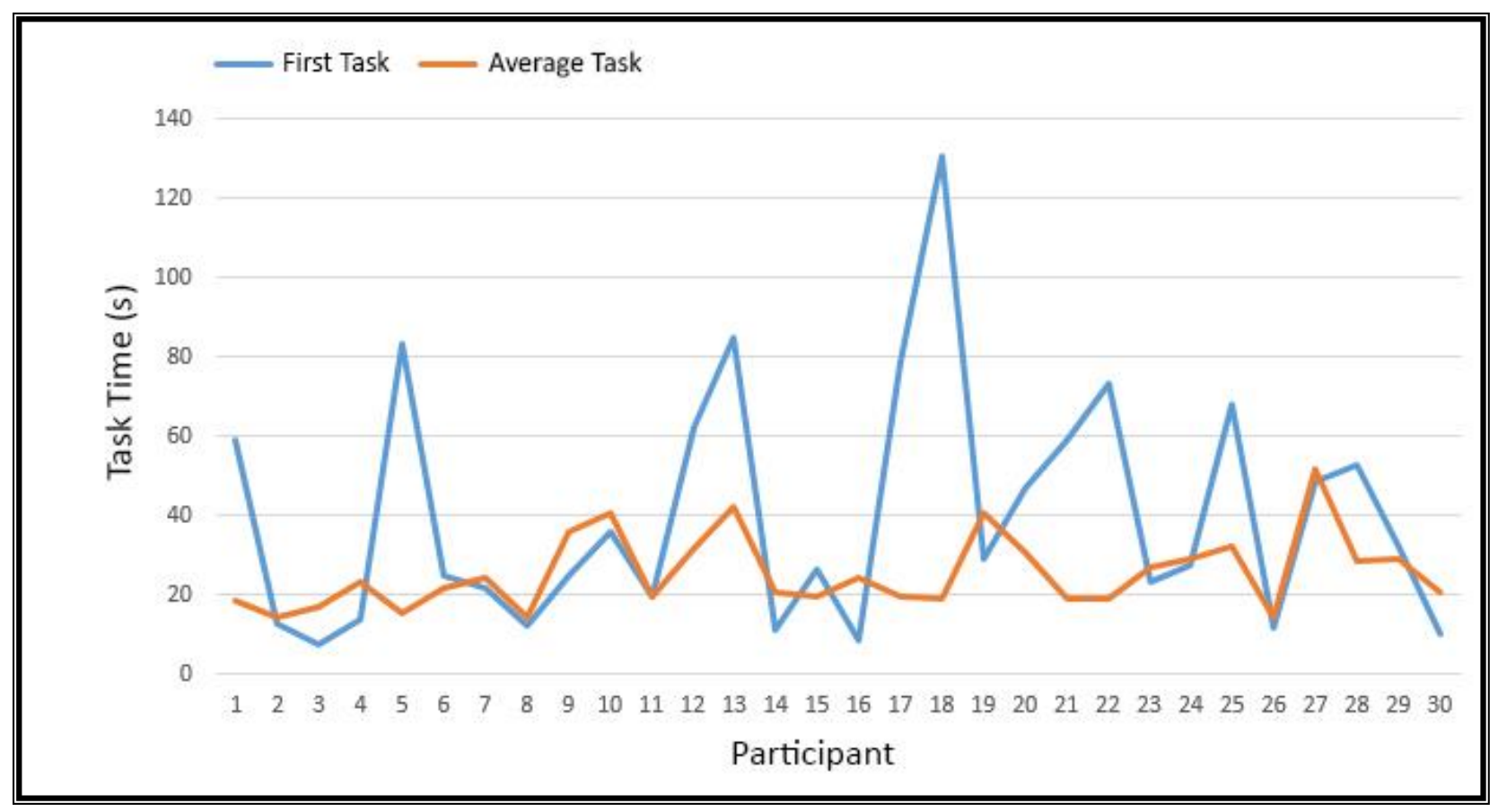

Figure 20: First Task vs. Average of Subsequent Tasks 
The timing data of the first tasks were then compared to the mean of all the remaining tasks (not including the first task) using a within-subject t-test to determine if there was a significant difference not accountable to individual differences (i.e. the difference is not accountable to an individual's level of expertise with the system, but the system itself). This was found to be significant at $\mathrm{p}<.05$ ( $\mathrm{t}$-value of 2.640795829 , $\mathrm{p}$-value of 0.013185 ). This shows a statistically observable difference between the timing data of first task recorded and the subsequent tasks completed, suggesting that the first-time user does, in fact, encounter at least some learning curve. The variance of the first task timing data was also higher when compared to all other tasks (variance 890 with SD of 29.8 , the variance of other tasks were all below 440 with standard deviations below 20).

It is safe to assume that at least some practice effect was occurring between tasks. If we observe the average time for tasks in the order they were completed, we can observe an obvious downward trend as in Figure 21:

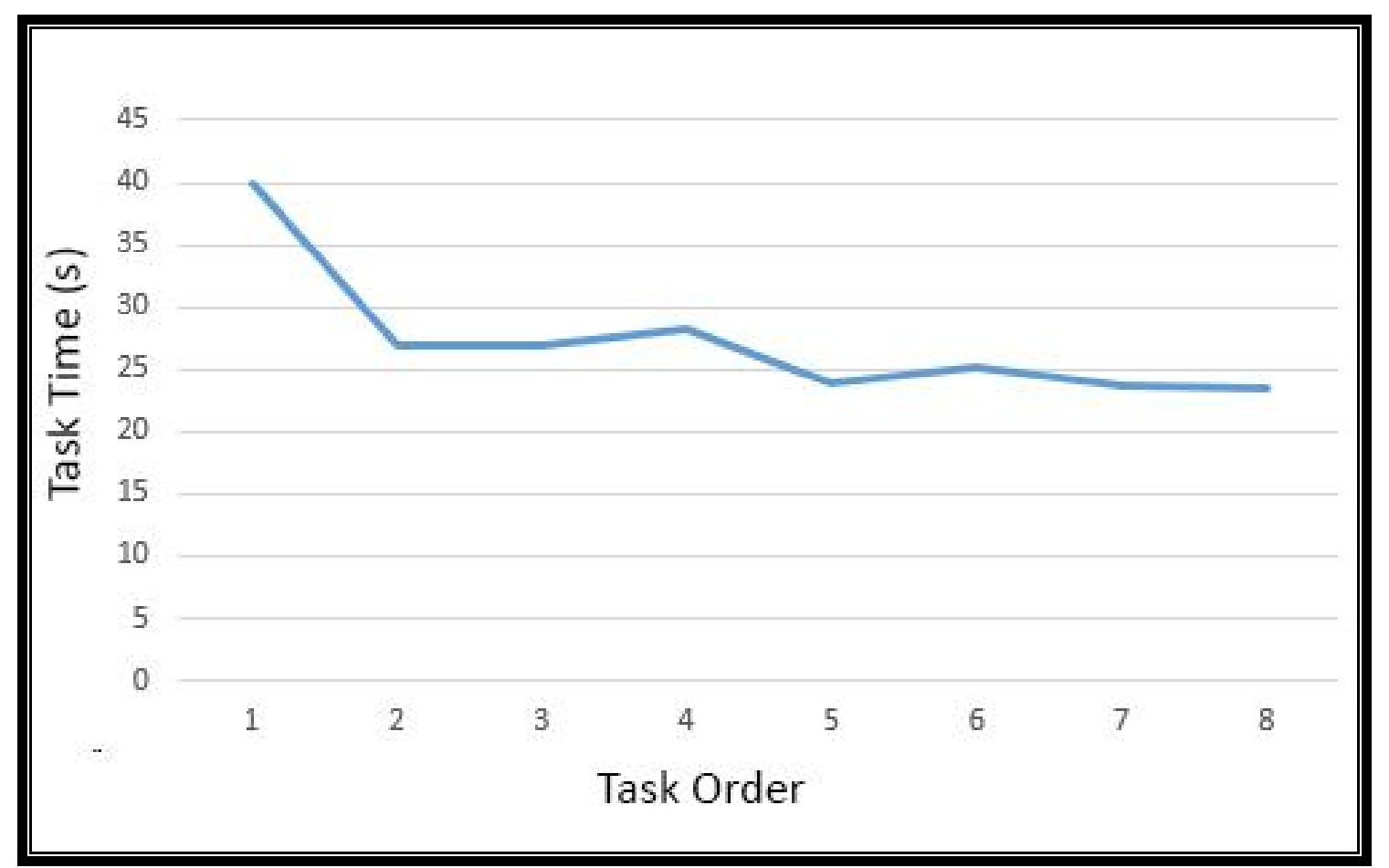

Figure 21: Average Task Time by Task Completion Order 
Comparing the mean performance on the first four tasks with the mean performance on the last four tasks, we see a greater significant difference (t-value of 2.964105416, p-value of 0.006013228). If we take the first four tasks as the learning time, this suggests that there is an average learning time of 122.01 seconds (the sum of the first four task means).

As we can see, the majority of learning occurs between the first and second tasks. To isolate this learning effect, all the statistical tests were completed again, this time removing the first completed task from the analysis.

When examining the mean task times, we again find insignificant values for perspective difference, and in fact find a much less significant comparison of the haptic feedback vibration (p-value of 0.793 versus the original p-value of 0.109 ).

If we compare the individual tasks that originally were approaching significance with all tasks (notably Vibration A vs. B with the Oculus implemented), we see a less significant result than before we took task learning into account (see Table 8 and Table 9). This might suggest that the vibration feedback is more effect at conveying the limitations of the robot when the user is still learning how to use the system, and its effectiveness decreases with experience.

\begin{tabular}{|c|c|c|c|}
\hline Task & t-value & p-value & Significance \\
\hline $\begin{array}{c}\mathbf{1}^{\text {st }} \text { vs 3 } 3^{\text {rd }} \text { person with } \\
\text { Gross Motor Task } \\
\text { and Vibration A }\end{array}$ & -0.1441 & 0.8875 & No \\
\hline $\begin{array}{c}\mathbf{1}^{\text {st }} \text { vs 3 } 3^{\text {rd }} \text { person with } \\
\text { Gross Motor Task } \\
\text { and Vibration B }\end{array}$ & -0.3107 & 0.7591 & No \\
\hline $\begin{array}{c}\mathbf{1}^{\text {st }} \text { vs 3 person with } \\
\text { Fine Motor Task } \\
\text { and Vibration A }\end{array}$ & 0.6992 & 0.4911 & No \\
\hline $\begin{array}{c}\mathbf{1}^{\text {st }} \text { vs 3 person with } \\
\text { Fine Motor Task } \\
\text { and Vibration B }\end{array}$ & -0.6274 & 0.5357 & No \\
\hline
\end{tabular}

Table 8: Perspective Comparison without Task Learning 


\begin{tabular}{|c|c|c|c|}
\hline Task & t-value & p-value & Significance \\
\hline $\begin{array}{c}\text { Vibration A vs. B } \\
\text { with } \\
\text { Gross Motor Task } \\
\text { Without Oculus }\end{array}$ & 0.3148 & 0.7579 & No \\
\hline $\begin{array}{c}\text { Vibration A vs. B } \\
\text { with }\end{array}$ & 1.3724 & 0.1838 & No \\
$\begin{array}{c}\text { Gross Motor Task } \\
\text { With Oculus }\end{array}$ & 0.1064 & & No \\
\hline $\begin{array}{c}\text { Vibration A vs. B } \\
\text { with }\end{array}$ & & 0.9162 & \\
$\begin{array}{c}\text { Fine Motor Task } \\
\text { Without Oculus }\end{array}$ & -1.9699 & & No \\
\hline $\begin{array}{c}\text { Vibration A vs. B } \\
\text { with }\end{array}$ & & 0.0588 & \\
\hline $\begin{array}{c}\text { Fine Motor Task } \\
\text { With Oculus }\end{array}$ & & & \\
\hline
\end{tabular}

Table 9: Vibration Comparison without Task Learning

Although an objective of this research was to determine if the system could be used intuitively without practice, in order to isolate this practice effect it is suggested that future research either includes a learning period before task assignment or compares tasks that are considerably different in assigned objective actions.

\subsubsection{Self-reported results}

\subsubsection{Overview}

The main portion of the post-questionnaire consisted of questions on a five-point Likert scale and therefore any of the self-reported findings come from ordinal data. The scale ranged from "Strongly Disagree" with a code of 1 to "Strongly Agree" with a code of 5. In order to determine consensus, mode and interquartile range (IQR) were calculated for each item since comparing means would not be valid for ordinal data. There were also open-ended long-form questions where the participants could voice any opinions or concerns, however these are less 
useful in terms of numerical analysis. The summary of the post-study questionnaire sorted by question subject can be seen in Appendix D.

The post-questionnaire questions were grouped into 4 categories or aspects of the experiment for the participant to focus on: motion control, haptic feedback, perspective and general questions. Within these categories the questions were given in random order in an attempt to avoid leading answers or carryover effects.

Inverted and redundant questions were also employed to help determine reliability. Redundant questions were slightly rephrased versions of the same question while keeping the core subject intact. (e.g. "I found it easier to control the robot's movements from a first-person perspective" and "It was easier to visualize how I needed to move with the Oculus headset"). Inverted questions were rephrased to address the same core subject in reverse (e.g. "Controlling the robot was confusing" versus "I found the use of the motion controllers to be intuitive").

\subsubsection{Motion Control}

The strongest consensus found on the post-questionnaire was in regards to the motion control. $83 \%$ of respondents agreed that the motion control was intuitive, with no respondents disagreeing with that claim (with a strong consensus indicated by an IQR of 0 ). This would indicate some degree of success in the original goal outlined in the problem statement of creating a system intuitive enough to be controlled without training. Confirmation can be found when examining the rephrased question with the same core topic; "I was easily able to understand the way the robot moved in relation to my own movements" which had 21 users agree with a mode of 4/"agree" and an IQR of 1.75 .

\subsubsection{Perspective}

Another polarised finding is the consensus that the use of the Oculus Rift headset was beneficial to the experience, to which 23 users agreed with a mode of 4/"agree" and an IQR of 0 , indicating a strong consensus. This finding seems to be confirmed if we examine the inverted questions for reliability, such as: "I preferred to not wear the Oculus headset when completing 
the tasks" (mode of 2/"disagree", IQR of 1.75) or "I found that the Oculus headset hindered my ability to control the robot" (mode of 2/"disagree", IQR of 0.75 ).

When asked about perspective specifically, users reported that it was easier to visualize how to move (mode of 4/"agree", IQR of 2) and easier to control (mode of 4/"agree", IQR of 2) from a first-person perspective, although the consensus is not as strong.

\subsubsection{Haptic Feedback}

The haptic feedback was the core topic with the most discordant opinions received on the post-questionnaire.

There was a disparity of preference for Vibration A, with 13 respondents preferring it to Vibration B, which 6 respondents preferred (although the mode response was neutral, with 11 respondents).

For questions regarding the understanding of the vibration signals, there was more confusion than understanding, as in the question "I was easily able to tell what the vibration signal meant" with 16 users disagreeing (mode of 2/“disagree", IQR of 2). This finding was corroborated in the inverted question "I couldn't tell which sensor the vibration was indicating", with 15 users agreeing (mode of 4/“agree”, IQR of 1.75).

The strongest consensus found for vibration comes from the question "The vibration feedback made me more likely to think a task wasn't possible", which was disagreed or strongly disagreed with by 19 respondents with an IQR of 1 and a mode of 2/“disagree”. 


\section{Chapter: Conclusions}

\subsection{Prototype Viability}

In this paper, we have presented a viable prototype for using an IMU sensor motion capture system to control a humanoid robot through a series of tasks. This prototype lends itself to a degree of scalability by design, and limitations of this design have been discussed. The accessibility of the design makes it highly suitable for future research.

Unrelated to the original hypotheses, it was found that a significant amount of task learning occurred when comparing a user's first completed task with subsequent tasks. The disparity in task completion times leveled off after the fourth task on average, with the greatest learning effect occurring between the first and second tasks. This task learning may have affected other results in our comparison.

None of the participants in this study disagreed with the statement that the control scheme was intuitive. As well, we found an average learning time of only 122 seconds and a significant difference in task completion times after only 4 trials, suggesting a highly intuitive system. With respect to the problem statement, this can be claimed as a successful demonstration. We have in fact created a system that can be used intuitively by untrained users.

The first hypothesis stated that first-person perspective would result in lower task completion times for fine motor tasks. Although a significant correlation could not be found in the task times, a significance was found in the self-reported post-study questionnaire, where the majority of participants found the control and movement visualization easier from a first-person perspective.

The second hypothesis described a preference for binary vibration feedback over strength-location based feedback. A significant preference for Vibration A over Vibration B was found for tasks that require fine motor control and a first-person perspective. This preference was not found when a significance comparison was completed for the two variables in any other task. When task learning was taken into account the significance was removed completely, suggesting the preference for Vibration A may only occur during the learning 
period. Self-reported findings regarding the haptic feedback were also much more diverse, without a strong consensus, although binary vibration was found to be slightly preferred. More than half of users indicated some difficulty in interpreting the haptic feedback signals.

\subsection{Discussion}

\subsubsection{Limitations}

Aside from the limitations of the device mentioned earlier in Section 3.1.7, in retrospect some limitations of this experiment could be further avoided with proper preparation. These limitations are described below.

The prototype would do well with a more robust design to prevent breakage and provide more accuracy in moving parts. Perhaps a better design would include a metal skeletal structure with 3D printed components as in the Telebot design [16], or certain key parts printed with higher strength materials such as the gearboxes or pivot joints.

The study could be conducted while minimizing task learning by providing a significant training period before entering the testing phase. However, since the target application for this device is for telepresence and not for the robot to learn any specific task, training a participant in specific tasks may be irrelevant or even counterproductive.

It is possible that the experiment design was overcomplicated, in that the user was introduced to too many new concepts at once, such as haptic feedback, telepresence and motion control, possibly straining focus limits and causing distraction from certain variables. The concept of attention strain, focus and cognitive load should be explored further, or perhaps the variables in the experiment should be isolated from each other in separate samples or tasks.

It is also possible that presenting many new concepts at once to the user caused a novelty factor, wherein the participant focused on different technologies they had not seen before more than the task at hand. Evidence of this can be seen in the participant's unanimous endorsement of the Oculus headset even though it did not provide any observable empirical advantage to completing the tasks given. The novelty factor for the participant may have been distracting and thus affected task completion times, although this relationship was not explored. 
In retrospect, a more complete analysis of the vibration haptic feedback would have included a control task without any feedback whatsoever. It is possible that the assumption taken from previous literature that including feedback is ideal is incorrect. Perhaps the visual confirmation of movement by itself would have given significantly different task completion times than when including vibration. Discarding this assumption would have given a more complete conclusion, and would have allowed us to further examine the role of haptic feedback in motion-controlled robotics.

\subsubsection{Future Research}

Many objectives for future research are born out of the limitations of this experiment.

It is possible that this type of control may be more suited to a different type of feedback, such as a visual overlay in the VR headset, a sound trigger, or a different type of haptic feedback entirely. These different feedbacks could be researched and compared to determine their effectiveness in relaying an avatar's range limitations. Feedback could be refined to eliminate the problem of confusion possibly caused by a disconnect between robotic movement and sensor feedback due to the latency of the servo movement. It is also possible that the feedback was further ignored due to a focus on the robot motion, and the fact that there were no ill effects for leaving the range of motion boundary aside from the vibration (i.e. the robot did not break or stop completely if it was still "catching up").

We have confirmed the problem of individual differences in motion control as described in [14], and more work should be done to extract these differences to find stronger correlations. This could be done by using a much greater sample size, or isolating the different variables in separate trials (i.e. different samples for individual variables like vibration and perspective).

As our system currently stands, the jacket is tethered to a power source and serial cable to effectively allow haptic feedback. Creating a completely wireless solution would leverage the benefits of the IMU system being effective in different environments. This would also allow the user to move around the capture space, providing an opportunity into researching a comparison between self-guided viewpoints, among other questions this freedom provides. 
While it is possible that a first-person perspective may be more effective at conveying a sense of presence in telepresence robotic operations [32], this was irrelevant to the hypothesis which regarded task completion times as proof of competency, and thus was not fully explored. It is possible an increased feeling of presence would be beneficial to control times. It would also be interesting to observe if there is a significant difference in control ability when the user is positioned in the same room as the telepresence robot as opposed to a virtual view.

In order to curb the novelty factor, perhaps a longitudinal study could be completed, though task learning may confound this as well and would need to be sufficiently eliminated.

\subsubsection{Prototype Adaptation / Scalability}

One of the benefits of an IMU motion capture system is that it is easily scalable by adding or removing sensors, and thus adding or removing captured joints. The prototype could easily be adapted to capture more limbs such as the second arm, head, neck, torso or legs, and add this data to the capture. The robot could also be upgraded to allow for more degrees of freedom and points of rotation, and use similar tracking data. 


\section{References}

[1] D. Arsenault, “A Quaternion-Based Motion Tracking and Gesture Recognition System Using Wireless Inertial Sensors”, Master's Thesis, Carleton University, Ottawa, 2014.

[2] A. Godwin, M. Agnew, and J. Stevenson, "Accuracy of inertial motion sensors in static, quasistatic, and complex dynamic motion," Journal of Biomechanical Engineering, vol. 131 , no. 11, 2009.

[3] K. O’Donovan, R. Kamnik, D. O’Keeffe, and G. Lyons, “An Inertial and Magnetic Sensor Based Technique for Joint Angle Measurement," J. Biomech., vol. 40, pp. 26042611, 2007.

[4] M.A. Brodie, A. Walmsley, and W. Page, "Dynamic Accuracy of Inertial Measurement Units During Simple Pendulum Motion," Comput. Methods Biomech. Biomed. Eng., vol. 11, pp. 235-242, 2008.

[5] H.J. Luinge, P.H. Veltink, and C.T. Baten, "Ambulatory Measurement of Arm Orientation," J. Biomech., vol. 40, pp. 78-85, 2007.

[6] N. Pollard, J. Hodgins, M. Riley, and C. Atkeson, "Adapting human motion for the control of a humanoid robot," Proceedings of ICRA'02, IEEE International Conference on Robotics and Automation, 2002.

[7] H. Shin, J. Lee, M. Gleicher, and S. Shin, "Computer puppetry: An importance-based approach,” ACM Transactions on Graphics, April 2001.

[8] Oculus VR, “Oculus Rift,” 2015. [Online]. Available: http://www.oculusvr.com.

[9] Vicon, "What is motion capture?," 2015. [Online] Available: http://www.vicon.com/what-is-motion-capture.

[10] Windolf, Markus, N. Götzen, and M. Morlock. "Systematic accuracy and precision analysis of video motion capturing systems - exemplified on the Vicon-460 system," Journal of Biomechanics, vol. 41, no. 12, pp. 2776-2780, 2008.

[11] P.F. Yang, M. Sanno, G.P. Brüggemann, and J. Rittweger, "Evaluation of the performance of a motion capture system for small displacement recording and a discussion for its application potential in bone deformation in vivo measurements," 
Proceedings of the Institution of Mechanical Engineers, Part H: Journal of Engineering in Medicine vol. 226.11, pp. 838-847, 2012.

[12] C. Novo, S. Alharbi, M. Fox, E. Ouellette, E. Biden, M. Tingley, and V. Chester, "The impact of technical parameters such as video sensor technology, system configuration, marker size and speed on the accuracy of motion analysis systems," Ingeniería Mecánica. Tecnología y Desarrollo, vol. 5.1, pp. 265-271, 2014.

[13] X. Chen, and J. Davis. "Camera placement considering occlusion for robust motion capture," Computer Graphics Laboratory, Stanford University, Tech. Rep 2.2.2, pp. 2, 2000.

[14] D. Vlasic, R. Adelsberger, G. Vannucci, J. Barnwell, M. Gross, W. Matusik, and J. Popovic, "Practical motion capture in everyday surroundings," ACM Transactions on Graphics (TOG). vol. 26, no. 3, 2007.

[15] N. Miller, O. C. Jenkins, M. Kallmann, and M. J. Matric, "Motion capture from inertial sensing for untethered humanoid teleoperation," International Conference of Humanoid Robotics, pp. 547-565, 2004.

[16] M. Prabakar, and J. H. Kim, "TeleBot: Design Concept of Telepresence Robot for Law Enforcement," Proceedings of the 2013 World Congress on Advances in Nano, Biomechanics, Robotics, and Energy Research (ANBRE 13), Seoul, Korea, 2013.

[17] A. Whitehead, H. Johnston, K. Fox, N. Crampton, and J. Tuen, "Homogeneous accelerometer-based sensor networks for game interaction," Computers in Entertainment (CIE) vol. 9, no.1, pp. 1, 2011.

[18] A. Whitehead, N. Crampton, K. Fox, and H. Johnston, "Sensor networks as video game input devices," Proceedings of the 2007 conference on Future Play, ACM, 2007.

[19] C. Burt, "Having Fun, Working Out: Adaptive and Engaging Video Games for Exercise," Master's Thesis, Carleton University, Ottawa, 2014.

[20] National Aeronautics and Space Administration, "Robonaut," 2015. [Online]. Available: http://robonaut.jsc.nasa.gov/.

[21] FitBit, "FitBit Tracker Comparison," 2015. [Online]. Available: http://www.fitbit.com/ca/compare. 
[22] Fortune, "Fitbit files for $\$ 100$ million IPO, shows big profits," 2015. [Online]. Available: http://fortune.com/2015/05/07/fitbit-files-for-100-million-ipo/.

[23] Google, "Google Glass,” 2015. [Online]. Available: http://www.google.com/glass/.

[24] M. Obaid, M. Häring, F. Kistler, R. Bühling, and E. André, "User-defined body gestures for navigational control of a humanoid robot," Social Robotics, Springer Berlin Heidelberg, 2012.

[25] K. M. Tsui, M. Desai, H. Yanco, and C. Uhlik, "Exploring use cases for telepresence robots," International Conference on Human-Robot Interaction (HRI), 2011.

[26] D. Sakamoto, T. Kanda, T. Ono, H. Ishiguro, and N. Hagita, "Android as a Telecommunication Medium with a Human-like Presence," In Proc. of Intl. Conf. on Human-Robot Interaction, pp. 193-200, 2007.

[27] W. Wang, and L. Fu, "Mirror therapy with an exoskeleton upper-limb robot based on IMU measurement system," Proceedings of International Workshop on Medical Measurements and Applications (MeMeA), 2011.

[28] A. Kristoffersson, K. S. Eklundh, and A. Loutfi, "Measuring the quality of interaction in mobile robotic telepresence: a pilot's perspective, "International Journal of Social Robotics vol. 5, no. 1, pp. 89-101, 2013.

[29] D. Sakamoto, K. Takayuki, T. Ono, H. Ishiguro, and N. Hagita, "Android as a telecommunication medium with a human-like presence," 2nd ACM/IEEE International Conference on Human-Robot Interaction (HRI), 2007.

[30] Microsoft, "Kinect for Windows Features," 2015. [Online]. Available: https://www.microsoft.com/en-us/kinectforwindows/meetkinect/features.aspx

[31] Z. Zhang, "Microsoft kinect sensor and its effect," MultiMedia, IEEE, vol. 19, no. 2, pp. 4-10, 2012.

[32] J. Sugiyama, and J. Miura, "A wearable visuo-inertial interface for humanoid robot control," Proceedings of the 8th ACM/IEEE international conference on Human-robot interaction, 2013. 
[33] M. Hussein, "Motion Control of Robot by using Kinect Sensor," Research journal of applied sciences, engineering and technology, vol. 8, no. 11, pp. 1384 -1388, 2014.

[34] G. Du, P. Zhang, J. Mai, and Z. Li, "Markerless Kinect-based hand tracking for robot teleoperation," International Journal of Advanced Robotic Systems, vol. 9, no. 10, 2012.

[35] M. Parzych, A. Dabrowski, and D. Cetnarowicz, "Aspects of Microsoft Kinect sensor application to servomotor control," Bulletin of the Polish Academy of Sciences Technical Sciences, vol. 62, no. 3, pp. 595-601, 2014.

[36] M. Manigandan, and M. Jackin, "Wireless vision based mobile robot control using hand gesture recognition through perceptual color space," International Conference on Advances in Computer Engineering (ACE), 2010.

[37] H. Reddivari, C. Yang, Z. Ju, P. Liang, Z. Li, and B. Xu, "Teleoperation control of Baxter robot using body motion tracking," International Conference on Multisensor Fusion and Information Integration for Intelligent Systems (MFI), 2014.

[38] H. Jun, "The effect of composite vs. first person perspective view in real world telerobotic operations," Master's Thesis, Iowa State University, 2011.

[39] F. Okura, Y. Ueda, T. Sato and N. Yokoya, "Teleoperation of mobile robots by generating augmented free-viewpoint images," International Conference on Intelligent Robots and Systems (IROS), 2013.

[40] N. Vinson, J. Lapointe, A. Parush, and S. Roberts, "Cybersickness induced by desktop virtual reality," Proceedings on Graphics Interface, pp. 69-75, 2012.

[41] L. Rebenitsch, and C. Owen, "Individual variation in susceptibility to cybersickness," Proceedings of the 27th annual ACM symposium on User interface software and technology, 2014.

[42] Y. Rybarczyk, T. Coelho, T. Cardoso, and R. De Oliveira, "Effect of avatars and viewpoints on performance in virtual world: efficiency vs. telepresence," EAI Endorsed Transactions on Creative Technologies, vol. 14, no.1, pp. e4, 2014.

[43] G. Langevin, "InMoov,” 2015. [Online]. Available: http://www.inmoov.fr/project/.

[44] Precision Microdrives, "Driving Vibration Motors with Pulse Width Modulation," 2015. [Online]. Available: http://www.precisionmicrodrives.com/application-notes-technical- 
guides/application-bulletins/ab-012-driving-vibration-motors-with-pwm.

[45] Solarbotics, "VPM2 Vibrating Disk Motor Datasheet," 2015. [Online]. Available: https://solarbotics.com/download.php? file=159.

[46] Arduino, "Arduino - Introduction," 2015. [Online]. Available: https://www.arduino.cc/en/guide/introduction.

[47] S. Davis, K. Nesbitt, and E. Nalivaiko, "Comparing the onset of cybersickness using the Oculus Rift and two virtual roller coasters," Proceedings of the 11th Australasian Conference on Interactive Entertainment (IE 2015), vol. 27, 2015.

[48] R. El-laithy, J. Huang, and M. Yeh. "Study on the use of Microsoft Kinect for robotics applications," Position Location and Navigation Symposium (PLANS), 2012.

[49] C. Liying, Q. Sun, H. Su, Y. Cong, and S. Zhao, "Design and implementation of humanrobot interactive demonstration system based on Kinect," Control and Decision Conference (CCDC), 2012.

[50] K. Qian, J. Niu, and H. Yang, "Developing a gesture based remote human-robot interaction system using Kinect," International Journal of Smart Home, vol. 7, no. 4, 2013.

[51] M. Van den Bergh, D. Carton, R. De Nijs, N. Mitsou, C. Landsiedel, K. Kuehnlenz, D. Wollherr, L. Van Gool, and M. Buss, "Real-time 3D hand gesture interaction with a robot for understanding directions from humans," In RO-MAN, IEEE, 2011.

[52] D. Thewlis, C. Bishop, N. Daniell, and G. Paul, "Next generation low-cost motion capture systems can provide comparable spatial accuracy to high-end systems," Journal of applied biomechanics, vol. 29, no. 1, pp. 112-117, 2013.

[53] C. Han, S. Kim, C. Oh, P. Seo, D. Hong, and Y. Ryu, "The study of improving the accuracy in the 3D data acquisition of motion capture system," Second International Conference on Future Generation Communication and Networking Symposia, 2008.

[54] A. Staranowicz, G. R. Brown, and G. Mariottini, "Evaluating the accuracy of a mobile Kinect-based gait-monitoring system for fall prediction," Proceedings of the 6th International Conference on Pervasive Technologies Related to Assistive Environments, 
2013.

[55] G. Charness, U. Gneezy, and M. A. Kuhn, "Experimental methods: Between-subject and within-subject design," Journal of Economic Behavior \& Organization, vol. 81, no. 1, pp. $1-8,2012$.

[56] A. M. Khan, Y-K. Lee, S. Y. Lee, and T-S. Kim, "Human activity recognition via an accelerometer-enabled-smartphone using kernel discriminant analysis," 5th International Conference on Future Information Technology (FutureTech), 2010.

[57] Y. Bai, S. Wu, and C. Tsai, "Design and implementation of a fall monitor system by using a 3-axis accelerometer in a smart phone," IEEE Transactions on Consumer Electronics, vol. 58, no. 4, pp. 1269-1275, 2012.

[58] Y. Lee, and S, Cho, "Activity recognition using hierarchical hidden markov models on a smartphone with 3D accelerometer," Hybrid Artificial Intelligent Systems, Springer Berlin Heidelberg, pp. 460-467, 2011.

[59] J. Kwapisz, G. M. Weiss, and S. A. Moore, "Activity recognition using cell phone accelerometers," SigKDD Explorations Newsletter, vol. 12, no. 2, pp. 74-82, 2011.

[60] Y. He, Y. Li, and S. Bao, "Fall Detection by built-in tri-accelerometer of smartphone," International Conference on Biomedical and Health Informatics (BHI), 2012.

[61] G. Yavuz, M. Kocak, G. Ergun, H. O. Alemdar, H. Yalcin, O. D. Incel, and C. Ersoy, "A smartphone based fall detector with online location support," International Workshop on Sensing for App Phones, Zurich, Switzerland, 2010.

[62] Unity, "Unity," 2015. [Online]. Available: http://unity3d.com/.

[63] Oculus, "Unity Integration" 2015. [Online]. Available: https://developer.oculus.com/documentation/unity/latest/.

[64] Nintendo, "Nintendo Wii" 2015. [Online]. Available: http://wii.com/.

[65] B. Berman, "3-D printing: The new industrial revolution," Business horizons, vol. 55, no. 2, pp. 155-162, 2012.

[66] Hitec, "Hitec 645MG High Torque, Metal Gear Premium Sport,” 2015. [Online]. Available: http://hitecrcd.com/products/servos/sport-servos/analog-sport-servos/hs- 


\section{5mg-high-torque-metal-gear-servo/product}

[67] Hitec, "HS-805BB Mega Giant Scale Servo," 2015. [Online]. Available: http:/hitecrcd.com/products/servos/giant-servos/analog-giant-servos/hs-805bb-megagiant-scale-servo/product

[68] Microchip, "Motion Sensor Demonstration Board User's Guide," 2012. [Online]. Available: http://ww1.microchip.com/downloads/en/DeviceDoc/52114a.pdf

[69] A. Okamura, "Methods for haptic feedback in teleoperated robot-assisted surgery." Industrial Robot: An International Journal, vol. 31, no. 6, pp. 499-508, 2004.

[70] K. Kuchenbecker, J. Fiene, and G. Niemeyer, "Improving contact realism through eventbased haptic feedback." IEEE Transactions on Visualization and Computer Graphics, pp. 219-230, 2006.

[71] A. Kron, G. Schmidt, B. Petzold, M. Zah, P. Hinterseer, and E. Steinbach, "Disposal of explosive ordnances by use of a bimanual haptic telepresence system." International Conference on Robotics and Automation, 2004.

[72] H. Kozima, M. Michalowski, and C. Nakagawa, "Keepon.", International Journal of Social Robotics, vol. 1, no .1, pp. 3-18, 2009.

[73] S. Dubowsky, F. Genot, S. Godding, H. Kozono, A. Skwersky, H. Yu, and L. Shen Yu, "PAMM - a robotic aid to the elderly for mobility assistance and monitoring", In IEEE International Conference on Robotics and Automation, vol. 1, pp. 570-576, 2000.

[74] C. Burgar, P. Lum, P. Shor, and H. Van der Loos, "Development of robots for rehabilitation therapy", Journal of Rehabilitation Research and Development, vol. 37, no. 6, pp. 663-673, 2002.

[75] K. Wada, and T. Shibata, "Living with seal robots-its sociopsychological and physiological influences on the elderly at a care house." IEEE Transactions on Robotics, vol. 23, no. 5, pp. 972-980, 2007.

[76] D. Feil-Seifer, and M. Matarić, "Defining socially assistive robotics." International Conference on Rehabilitation Robotics, 2005. 


\title{
Appendices
}

\author{
Appendix A - Consent Form
}

Carleton

U N I V R S I T Y

Canada's Capital University

\section{Consent Form}

Title: Motion Control of a Physical Avatar with Haptic Feedback

Date of ethics clearance: 01/20/15

Ethics Clearance for the Collection of Data Expires: 05/31/15

I choose to participate in this study on motion control of a robotic avatar. The researcher for this study is Colin Killby in the School of Information Technology, working under the supervision of Dr. Anthony Whitehead.

This study involves one 60-minute session with a questionnaire at the end. The session will be broken into two consecutive 25-minute sessions. One 25-minute session will involve you wearing an Oculus Rift virtual reality headset to obtain a first-person perspective of the robot, and performing various tasks with the robot arm using motion controllers. The other 25 -minute session will be performing similar tasks, this time without the headset. After the sessions are complete, you will be asked to complete a 10-minute long questionnaire regarding the tasks completed and devices used in the sessions.

As this project will not ask you for any personal information, there is minimal risk to you, the participant. All information provided by you will be confidential and anonymous; your session results and questionnaire responses will not be linked to your name and they will not be shared.

This project requires you to use your left arm in order to control the robot, and so there is a small risk of arm strain. To further minimize this risk, we ask that you exercise caution and do not perform gestures that you think might cause strain and to stop if your arms become too tired to perform the tasks as assigned.

You have the right to end your participation in the study at any time, for any reason. If you withdraw from the study, all information you have provided will be immediately destroyed. 
All research data, including video-recordings, logs, and questionnaire data will be encrypted and password-protected, and will not be linked to you in any way. Any hard copies of data (including any handwritten notes or USB keys) will be kept in a locked cabinet at Carleton University. Research data will only be accessible by the researcher.

Once the project is completed, all research data will be will be securely destroyed (Electronic data will be erased and hard copies will be shredded).

If you would like a copy of the finished research thesis, you are invited to contact the researcher to request an electronic copy which will be provided to you. The results of this research project may also be used in journals and conferences.

This project was reviewed by the Carleton University Research Ethics Board, which provided clearance to carry out the research. Should you have questions or concerns related to your involvement in this research, please contact:

\section{REB contact information:}

Professor Andy Adler, Chair

Professor Louise Heslop, Vice-Chair

Research Ethics Board

Carleton University

1325 Dunton Tower

1125 Colonel By Drive

Ottawa, ON K1S 5B6

Tel: 613-520-2517

ethics@carleton.ca

\section{Researcher contact information:}

Colin Killby

Carleton University

School of Information Technology

Canal Building, Room 4112

1125 Colonel By Drive

Ottawa, ON K1S 5B6 Canada

Tel:

Email:colin.killby@carleton.ca
Supervisor contact information:

Dr. Anthony Whitehead

Carleton University

School of Information Technology

Canal Building, Room 4201

1125 Colonel By Drive

Ottawa, ON K1S 5B6 Canada

Tel: 613-520-2600 ext. 1696

Email: Anthony.Whitehead@carleton.ca

Do you agree to be video-recorded:

Yes No 
Signature of participant

Signature of researcher
Date

Date 


\section{Appendix B - Call for Participants}

\section{Carleton \\ U N I V E R S I T Y}

Canada's Capital University

\section{Call for Participants}

Title: Motion Control of a Physical Avatar with Haptic Feedback

We are currently looking for volunteers to participate in an academic study controlling a robotic avatar using motion control and virtual reality technologies.
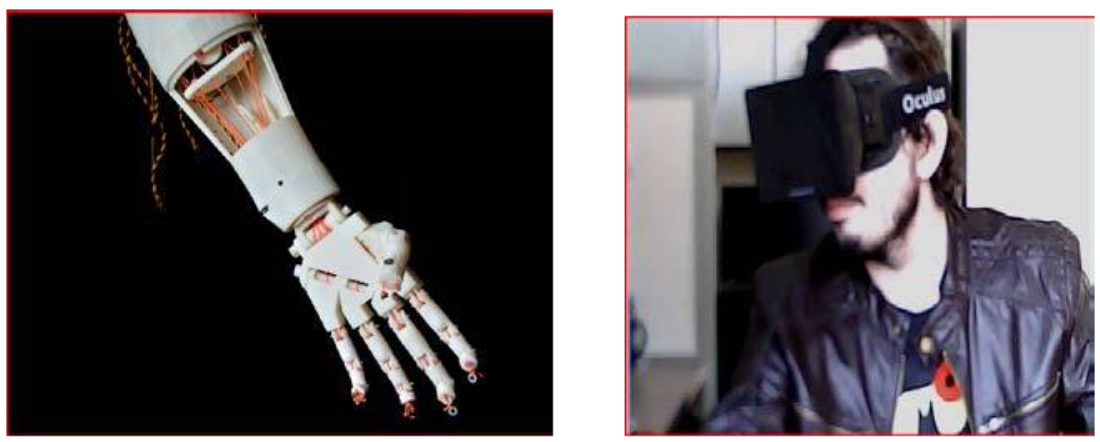

The study:

The study involves a 60-minute session involving the testing of a prototype of wearable technology that controls a robotic avatar, followed by a questionnaire. The testing entails completing several tasks using motion control to move a robot arm. No previous experience with motion-control or robotic technology is required.

This research has been reviewed and approved by the Carleton University Research Ethics Board. For more information please contact ethics@carleton.ca

To schedule a time to participate please send a message to the email colin.killby@carleton.ca with the subject: "research study" indicating availability. 


\section{Appendix C - Post-Study Questionnaire}

\section{Participant ID:}

For the following questions, please indicate the degree to which you agree or disagree with each statement by circling the appropriate number.

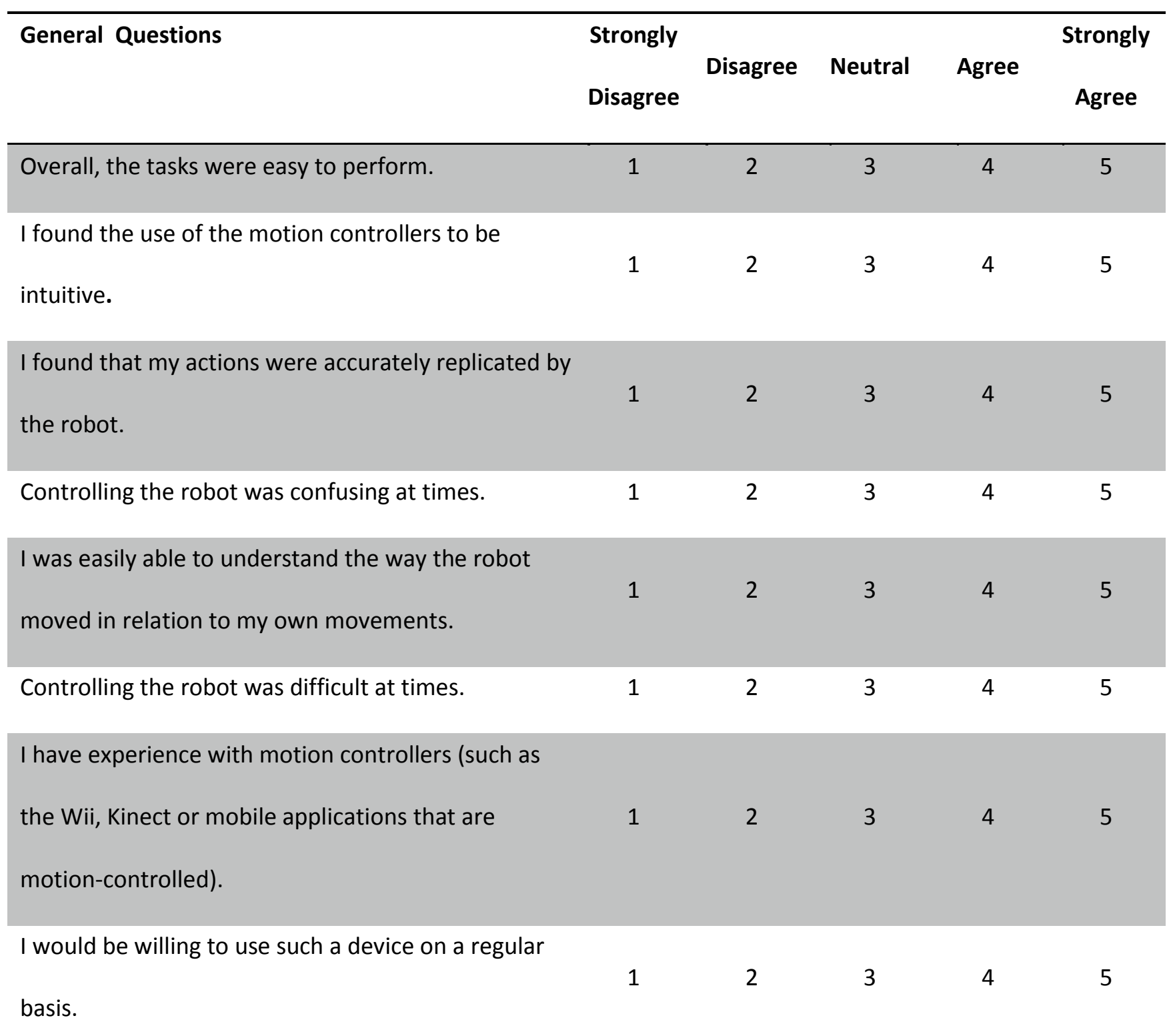




\begin{tabular}{llllll} 
I find it difficult to envision using such a device daily. & 1 & 2 & 3 & 4 & 5 \\
\hline
\end{tabular}

\begin{tabular}{|c|c|c|c|c|c|}
\hline Control Task Questions & $\begin{array}{l}\text { Strongly } \\
\text { Disagree }\end{array}$ & Disagree & Neutral & Agree & $\begin{array}{l}\text { Strongly } \\
\text { Agree }\end{array}$ \\
\hline $\begin{array}{l}\text { I found it easy to move the arm to where I wanted it } \\
\text { to go. }\end{array}$ & 1 & 2 & 3 & 4 & 5 \\
\hline I felt in control at all times. & 1 & 2 & 3 & 4 & 5 \\
\hline At times the robot did not move the way I expected. & 1 & 2 & 3 & 4 & 5 \\
\hline $\begin{array}{l}\text { I would have preferred an alternate form of control } \\
\text { to move the robot. }\end{array}$ & 1 & 2 & 3 & 4 & 5 \\
\hline $\begin{array}{l}\text { I found it difficult to position the arm exactly how I } \\
\text { wanted it. }\end{array}$ & 1 & 2 & 3 & 4 & 5 \\
\hline $\begin{array}{l}\text { It was easy for me to recognize when an object was } \\
\text { outside of the Robot's range of motion. }\end{array}$ & 1 & 2 & 3 & 4 & 5 \\
\hline $\begin{array}{l}\text { The vibration feedback made me believe an object } \\
\text { was outside of the robot's reach when it in fact } \\
\text { wasn't. }\end{array}$ & 1 & 2 & 3 & 4 & 5 \\
\hline
\end{tabular}

\section{Haptic Feedback Questions}

$\begin{array}{llll}\text { Strongly } & \text { Disagree Neutral Agree } \\ \text { Disagree } & & \end{array}$

Strongly

Agree 


\begin{tabular}{|c|c|c|c|c|c|}
\hline $\begin{array}{l}\text { I found VIBRATION A style to be more useful at } \\
\text { conveying limitations than the VIBRATION B. }\end{array}$ & 1 & 2 & 3 & 4 & 5 \\
\hline I was easily able to tell what the vibration signal meant. & 1 & 2 & 3 & 4 & 5 \\
\hline I found the vibration distracting. & 1 & 2 & 3 & 4 & 5 \\
\hline $\begin{array}{l}\text { I found that the vibration was useful in relaying the } \\
\text { limitations of the robot. }\end{array}$ & 1 & 2 & 3 & 4 & 5 \\
\hline $\begin{array}{l}\text { The vibration feedback helped me complete the } \\
\text { presented tasks. }\end{array}$ & 1 & 2 & 3 & 4 & 5 \\
\hline I couldn't tell which sensor the vibration was indicating. & 1 & 2 & 3 & 4 & 5 \\
\hline $\begin{array}{l}\text { The vibration feedback stopped me from moving in a } \\
\text { way I normally would. }\end{array}$ & 1 & 2 & 3 & 4 & 5 \\
\hline The vibration feedback made me more likely to think a & 1 & 2 & 3 & 4 & 5 \\
\hline
\end{tabular}

Oculus Headset Questions

I found it easier to control the robot's movements

from a first-person perspective.

I preferred to not wear the Oculus headset when

completing the tasks.

It was easier to visualize how I needed to move with

the Oculus headset.

$\begin{array}{llll}\text { Strongly } & & \\ & \text { Disagree Neutral Agree } \\ \text { Disagree } & & \end{array}$

Strongly

Agree

$\begin{aligned} & \text { I found it easier to control the robot's movements } \\ & \text { from a first-person perspective. }\end{aligned}$ 1
I preferred to not wear the Oculus headset when
completing the tasks.
It was easier to visualize how I needed to move with
the Oculus headset.


I found that the Oculus headset hindered my ability

to control the robot.

\section{I found the Oculus headset to be disorienting.}

The Oculus headset was beneficial to the experience.

\section{1}

2

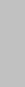

\section{3}

\section{4}

2

3

2

\section{Long-form questions}

1) Did you prefer controlling the robot with or without the Oculus headset? Why?

2) Which type of vibration feedback did you prefer? Why?

3) Have you used motion-controlled electronics before?

4) Which tasks in your daily life could you see yourself using this system for (at home or at work)?

5) How would you improve the controlling device if you could?

6) Would you prefer a different method of control? Which ones?

\section{Demographic Questions}

1) What is your age?

2) What is your gender? Male Female Other Prefer not to answer 
3) Are you left or right-handed? Left Right Ambidextrous 


\section{Appendix D - Likert Response Summary}

\begin{tabular}{|c|c|c|c|c|c|c|}
\hline $\begin{array}{l}\text { Question } \\
\text { Subject }\end{array}$ & MODE & \# Agree & $\begin{array}{l}\text { \# Strongly } \\
\text { Agree }\end{array}$ & \# Disagree & $\begin{array}{l}\text { \# Strongly } \\
\text { Disagree }\end{array}$ & IQR \\
\hline $\begin{array}{l}\text { Unwilling to } \\
\text { use daily }\end{array}$ & Disagree & 8 & 0 & 14 & 0 & 2 \\
\hline $\begin{array}{l}\text { Confusing } \\
\text { control }\end{array}$ & Disagree & 10 & 0 & 9 & 1 & 2 \\
\hline $\begin{array}{l}\text { Intuitive } \\
\text { control }\end{array}$ & Agree & 24 & 1 & 0 & 0 & 0 \\
\hline $\begin{array}{l}\text { Willing to } \\
\text { use daily }\end{array}$ & Agree & 15 & 3 & 5 & 0 & 1 \\
\hline $\begin{array}{l}\text { Understood } \\
\text { movement } \\
\text { control }\end{array}$ & Agree & 12 & 9 & 3 & 0 & 1.75 \\
\hline $\begin{array}{l}\text { Difficult } \\
\text { control }\end{array}$ & Agree & 18 & 0 & 3 & 0 & 1 \\
\hline Easy tasks & Agree & 20 & 3 & 0 & 0 & 0 \\
\hline $\begin{array}{l}\text { Actions } \\
\text { accurately } \\
\text { replicated }\end{array}$ & Agree & 18 & 0 & 2 & 0 & 1 \\
\hline $\begin{array}{l}\text { Motion- } \\
\text { control } \\
\text { experience }\end{array}$ & $\begin{array}{l}\text { Strongly } \\
\text { Agree }\end{array}$ & 10 & 13 & 3 & 3 & 1 \\
\hline $\begin{array}{l}\text { Felt in } \\
\text { control }\end{array}$ & Agree & 20 & 0 & 5 & 0 & 1 \\
\hline $\begin{array}{l}\text { Negative } \\
\text { feedback }\end{array}$ & Disagree & 8 & 0 & 10 & 2 & 2 \\
\hline $\begin{array}{l}\text { Unexpected } \\
\text { robot } \\
\text { movement }\end{array}$ & Agree & 17 & 3 & 5 & 1 & 1 \\
\hline $\begin{array}{l}\text { Difficult to } \\
\text { position }\end{array}$ & Agree & 18 & 3 & 3 & 0 & 1 \\
\hline $\begin{array}{l}\text { Prefer } \\
\text { alternate } \\
\text { control }\end{array}$ & Disagree & 2 & 0 & 15 & 3 & 1 \\
\hline $\begin{array}{l}\text { Easy to } \\
\text { understand } \\
\text { range }\end{array}$ & Agree & 11 & 2 & 9 & 1 & 2 \\
\hline $\begin{array}{l}\text { Easy to } \\
\text { position }\end{array}$ & Agree & 14 & 2 & 6 & 0 & 1 \\
\hline $\begin{array}{l}\text { Vibration } \\
\text { helpful }\end{array}$ & Disagree & 6 & 2 & 14 & 0 & 1.75 \\
\hline $\begin{array}{l}\text { Understood } \\
\text { vibration }\end{array}$ & Disagree & 6 & 3 & 14 & 2 & 2 \\
\hline
\end{tabular}




\begin{tabular}{|c|c|c|c|c|c|c|}
\hline $\begin{array}{l}\text { Distracting } \\
\text { vibration }\end{array}$ & Disagree & 7 & 0 & 13 & 4 & 1 \\
\hline $\begin{array}{l}\text { Unintelligible } \\
\text { vibration }\end{array}$ & Agree & 11 & 4 & 7 & 3 & 2 \\
\hline $\begin{array}{l}\text { Vibration A } \\
\text { preference }\end{array}$ & Neutral & 8 & 5 & 5 & 1 & 1 \\
\hline $\begin{array}{l}\text { Useful } \\
\text { vibration }\end{array}$ & Agree & 11 & 2 & 8 & 0 & 1.75 \\
\hline $\begin{array}{l}\text { Vibration } \\
\text { affected } \\
\text { motion }\end{array}$ & Disagree & 7 & 1 & 13 & 3 & 1.75 \\
\hline $\begin{array}{l}\text { Vibration } \\
\text { affected } \\
\text { perception }\end{array}$ & Disagree & 2 & 1 & 15 & 4 & 1 \\
\hline $\begin{array}{l}\text { Easier } \\
\text { visualization } \\
\text { with Oculus }\end{array}$ & Agree & 14 & 2 & 9 & 1 & 2 \\
\hline $\begin{array}{l}\text { Hindrance } \\
\text { with Oculus }\end{array}$ & Disagree & 4 & 2 & 16 & 5 & 0.75 \\
\hline $\begin{array}{l}\text { Oculus } \\
\text { Beneficial }\end{array}$ & Agree & 18 & 5 & 1 & 2 & 0 \\
\hline $\begin{array}{l}\text { Prefer no } \\
\text { Oculus }\end{array}$ & Disagree & 5 & 3 & 11 & 3 & 1.75 \\
\hline $\begin{array}{l}\text { Oculus } \\
\text { disorienting }\end{array}$ & Disagree & 4 & 2 & 14 & 2 & 1 \\
\hline $\begin{array}{l}\text { Easier with } \\
\text { Oculus }\end{array}$ & Agree & 9 & 6 & 9 & 1 & 2 \\
\hline
\end{tabular}




\section{Appendix E - Pre-Experiment Script}

\section{This script outlines major points to cover before starting the experiment and during testing.}

Begin by getting the participant to read and sign the consent form. Then have the participant sit in the experiment chair.

Make sure all of the following points are given verbally:

- Reassure the participant of the confidentiality of the experiment. If they gave consent to video recording, ensure that this will only be done from behind as a backup data collection source, and will be destroyed as soon as the data is confirmed to be acceptable so that confidentiality is maintained.

- Describe the control mechanism for the robot. Visually point to the joints of rotation of the robot arm, so that the participant understands what part of their body motion is being transferred. Show the participant the approximate range-of-motion they can expect using your own left arm as a visual aid.

- Describe the vibration feedback types. (Vibration A is a binary type, meaning no vibration will be felt until you leave the robot's range of motion. At that point the vibration motor will be at full strength. Vibration B will increase in vibration strength as you approach the range of motion boundary).

- Describe the two types of tasks that the participant will need to complete, with the actual objects they will need to manipulate. (Task 1 involves moving this cube off of this platform in any way you see fit. Task 2 involves placing at least one finger through the mug's handle, as if you were going to lift it. You do not need to actually lift the mug, as a single finger grip will be considered as task completion). 
- Before placing any apparatus on the participant, make sure you verbally describe what you are doing, and ensure that this does not cause discomfort. Help the participant put on the haptic jacket, and then affix the sensors to the jacket.

- Again ensure the comfort of the participant, and reiterate that if they feel discomfort or wish to terminate the session at any time, they may do so.

- Ask if the participant has any questions before beginning testing.

- Conduct testing. Before each task, announce the variables that are used (Vibration type, task objective, and perspective type). Ensure that the participant returns to the start position before each task start.

- After testing, ask the participant to complete the post questionnaire. Reassure them of their anonymity. The participant ID on the questionnaire is only to correspond the answers to the timing data, and can in no way compromise confidentiality.

- $\quad$ Ask if the participant has any questions or comments regarding the study. 